\title{
A Novel Tooth Tip Relief Method for Reducing Micro-Pitting of Spur Gears
}

\section{Xiangyang $\mathrm{Xu}$}

Beihang University

Yinghua Liang

Beihang University

Shumiao Zuo

Beihang University

Peng Dong ( $\nabla$ dongpengbeihang@163.com )

Beihang University

Yanfang Liu

Beihang University

Shuhan Wang

Beihang University

\section{Zhuo Wang}

State Key Laboratory of Smart Manufacturing for Special Vehicles and Transmission System

\section{Original Article}

Keywords: Tooth tip relief, Micro-pitting, Gear meshing simulation, Hertz contact stress, Smooth transition.

Posted Date: April 8th, 2021

DOI: https://doi.org/10.21203/rs.3.rs-371732/v1

License: (c) (i) This work is licensed under a Creative Commons Attribution 4.0 International License.

Read Full License 


\title{
A Novel Tooth Tip Relief Method for Reducing Micro-pitting of Spur Gears
}

\author{
Xiangyang Xu ${ }^{\text {a,b }}$ (xxy@ buaa.edu.cn), Yinghua Lianga,b (09330@buaa.edu.cn), Shumiao Zuo a,b

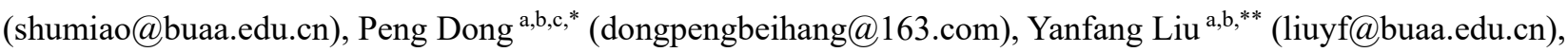 \\ Shuhan Wang ${ }^{\mathrm{a}, \mathrm{b}}$ (wshbeihang@163.com), Zhuo Wang ${ }^{\mathrm{c}}$ (wangzhuo0718@163.com) \\ a Department of Automotive Engineering, School of Transportation Science and Engineering, Beihang University, Beijing 100191, P.R. China \\ b Ningbo Institute of Technology, Beihang University, Ningbo 315832, P.R. China \\ c State Key Laboratory of Smart Manufacturing for Special Vehicles and Transmission System, Baotou City 014030, Inner Mogolia, P.R. \\ China
}

Abstract: Micro-pitting is a common fatigue failure mode of spur gears. To reduce it, this paper proposes a novel tooth tip relief method. Gear meshing simulation is firstly performed considering the actual contact path, showing that there are four Hertz contact stress peaks in the transition areas of the tooth flank. Equations are then developed for the novel tooth tip relief method: one focuses on the smooth transition between the involute profile and the tip relief region, the other on the smooth transition between the tip relief region and the tooth tip. The results of curvature radius and Hertz contact stress show that the proposed novel method can effectively reduce the Hertz contact stress peaks, which indicates this tip relief method could benefit for reducing the micro-pitting. Finally, both wear simulations and bench tests are conducted, verifying the effectiveness of the proposed method for reducing the micro-pitting of spur gears.

Key words: Tooth tip relief; Micro-pitting; Gear meshing simulation; Hertz contact stress; Smooth transition.

\section{Introduction}

Spur gears are widely used in heavy-load machinery, such as vehicles, railway equipment, ships, and wind turbines. In the meshing process of spur gears, various fatigue modes occur on the tooth surface owing to the complex and harsh working environment. Among them, micro-pitting is a predominant early stage fatigue mode in most engineering applications. Micro-pitting, manifest as matt patches in tooth-flank areas, causes unexpected vibration and noise $[1,2]$, and may propagate into macro-pitting, spall, and even tooth fracture [3], ultimately leading to the failure of the gears.

Recently, numerous studies on micro-pitting have been carried out, including contact stress, material properties, microstructure, tribological conditions and load, etc. Using a finite element elastic plastic contact model [4], Wang et al. [5] found that rolling contact fatigue decreases as tensile stress increases. Roy et al. [6] found that greater retention of austenite leads to reduce micro-pitting with the same cycles. In addition, studies on the microstructure of the gear surface [7-9] have revealed that the anisotropy and randomness of the crystal plasticity result in variations in the crack initiation 


\begin{tabular}{|c|c|}
\hline \multicolumn{2}{|l|}{ Nomenclature } \\
\hline$a$ & Center distance \\
\hline$b$ & Tooth width \\
\hline$C_{a}$ & Amount of tooth tip relief \\
\hline$C_{l}$ & Starting positions of the arctangent proportional tip relief \\
\hline$c$ & Constant coefficient of arctangent proportional tip relief \\
\hline$d_{a}$ & Tip diameter \\
\hline$F$ & Force on the tooth \\
\hline$i_{G}$ & Transmission ratio \\
\hline$L$ & Backlash of the gears \\
\hline$l_{\text {eff }}$ & Effective tooth width \\
\hline$l_{r}$ & Starting positions of the progressive fillet \\
\hline$m_{n}$ & Normal modulus \\
\hline$p$ & Hertz contact stress \\
\hline$R_{a}$ & Average roughness \\
\hline$R_{\mathrm{S}}$ & Crack criterion \\
\hline$r$ & Flank radius \\
\hline$r_{k}$ & Radius of tooth tip fillet \\
\hline$W$ & Comprehensive deformation of the meshing tooth at the contact point \\
\hline$w_{t b}, w_{t s}, w_{t r}, w_{r}$ & Different kind of tooth deformation \\
\hline$X_{a}$ & Height coordinate of arctangent proportional tip relief \\
\hline$X_{b}$ & Height coordinate of progressive fillet \\
\hline$x, y$ & Cooradinate of the point \\
\hline$z$ & Tooth number \\
\hline$\alpha$ & Slope angle \\
\hline$\alpha_{n}$ & Normal pressure angle \\
\hline$\Delta_{s, 1}$ & Profile deviation by arctangent-proportional tip relief \\
\hline$\Delta_{s, 2}$ & Profile deviation by progressive fillet \\
\hline$\delta$ & Position angle \\
\hline$\theta_{\text {oil }}$ & Lubricate temperature \\
\hline$v_{\theta}$ & Kinematic viscosity \\
\hline$\rho$ & Curvature radius \\
\hline$\rho_{15}$ & Density of lubricant \\
\hline$\varphi$ & Rotation angle \\
\hline $\mathbf{A}, \mathbf{E}$ & Position of engaging-in and out \\
\hline B, D & Transition position between single and double-tooth contact \\
\hline C & Pitch point \\
\hline \multicolumn{2}{|l|}{ Suffixes } \\
\hline$P$ & Refers to contact point \\
\hline 1,2 & Refers to the pinion and the wheel \\
\hline ini & Refers to the initial position \\
\hline$H$ & Refers to the Hertz contact \\
\hline
\end{tabular}

position. Tribological [10] and mixed lubrication conditions [11] also play important roles in the initiation and propagation of micro-pitting in the tooth flank. Zhang et al. [12] found that the root of the mean square of the surface roughness significantly influenced the competition between micro-pitting and pitting. In a study by Morales-Espejel et al. [13], the contact sliding speed, pressure and specific film thickness influenced the final damage level of micro-pitting based on a stable lubrication condition. However, a remarkable study by Li et al. [14] revealed the dynamic relationship between contact stress and lubrication conditions, suggesting a dynamic model for micro-pitting. The effects of microscale surface irregularities on micro-pitting were also discussed by Moorthy et al. [15]. 
Many methods to reduce micro-pitting have been proposed, and improvement of surface [16] and tribological [17] qualities are the most widely applied. The hindering of austenite retention in the micro-pitting of carburized steel was investigated by Roy et al. [18] under boundary lubrication conditions. An ultrasonic nanocrystal surface modification technique by Qin et al. [19] can be used to reduce the surface roughness to reduce micro-pitting. Furthermore, surface coatings [20-22] have also been proved effective in mitigating micro-pitting. Different lubricant additives [23] added in a base of low viscosity polyalphaolefin also influenced the micro-pitting with different degrees.

Previous studies [24-26] have indicated that contact stress contributes to micro-pitting, and that this stress is determined by the instantaneous meshing state of the gear pair. Many papers have also reported that the load distribution [27] was improved by influencing the meshing state through proper tooth tip relief. Although it is not the same as reducing the micro-pitting of the tooth surface directly, using tooth tip relief to influence the meshing state will also affect the contact stress, thereby affecting the micro-pitting. In fact, a proper tooth tip relief is a relatively economical method to prevent micro-pitting in engineering practice. Optimal tooth tip relief [28] results in better lubrication behaviors for reducing micro-pitting of gears, as has been proved by rigorous experiments. Simon [29] presented a linear function for the simultaneous calculation of optimal tooth tip relief and tooth crowning for spur and helical gears, which improved the load and stress distribution considerably. Ni et. al [30,31] improved the contact performance by a parabolic tip relief by a numerical design approach based on the gear-manufacturing and meshing theory. The dynamic responses of low contact ratio spur gear by linear and parabolic tip relief [32] have been compared for the minimum dynamic load of gears under different working conditions. The width modification of a spur gear [33] can reduce the micro-pitting by eliminating the Hertz contact stress. Mao [34] considered not only tooth tip relief but also lead crowning in the face-width direction to be highly accurate modification methods for reducing gear surface pitting, but this research lacked bench test verification. Bruyere et al. [35] analyzed the combination of profile relief and lead crowns in narrow-faced helical gears.

Linear tip relief, widely used in engineering applications, is an effective and economical method for reducing micropitting, but it leads to an increase in the local Hertz contact stress at the transition area between the involute profile and the tip relief region. Thus, the micro-pitting risk of this area increases considerably. Parabolic tip relief achieves a smooth transition between the tip relief region and the involute profile, but the Hertz contact stress is quite large when the gear comes into engagement because less material is removed at the tip relief region. Actually, parabolic tip relief is rarely used in theoretical and practical applications because of its complex manufacturing method and limited reduction of micro-pitting. 
In order to reduce the stress peaks in the tip relief transition areas, a novel tooth tip relief method for spur gears is proposed in this paper. The main contributions of this paper are: (1) Considering the actual contact path, the gear meshing process is simulated for curvature radius, contact path and Hertz contact stress; (2) A new method including an arctangentproportional tip relief and a progressive fillet is modelled mathematically, and key parameters are recommended; (3) The tooth profile deviation is calculated based on a wear rate model, and bench tests are carried out to verify the effectiveness of the proposed tooth tip relief method compared with that of the linear tip relief.

The rest of this paper is organized as follows: Section 2 describes the gear meshing simulation considering the actual path of contact, which can be used to investigate the curvature radius and Hertz contact stress along the contact path after tooth deformation and tooth tip relief. Section 3 discusses the stress peaks caused by linear tip relief. Then, the equations for tooth tip relief are introduced, and values of the key parameters of the equations are recommended. A simulation model using tooth profile deviation to evaluate micro-pitting is established. Experiments to verify the effectiveness of the tooth tip relief method are described in Section 4. Section 5 presents the conclusions.

\section{Gear meshing simulation}

\subsection{Contact point}

Theoretically, the contact point of a gear pair moves along the line of action. However, advanced engaging-in and lagged engaging-out would occur due to tooth deformation, which contributes to micro-pitting. Fig. 1 shows the initial position in the meshing process and a later random one. The origin of the coordinate system is the rotational center of the pinion. Subscripts 1 and 2 denote pinion and wheel, respectively. The initial position is defined as when the contact point $\mathrm{P}\left(x_{p}, y_{p}\right)$ is located on the center line of the gear pair. For a random position, the position angles between the center line and the point are $\delta_{1 / 2}$. P will be added to the subscript when the symbol specifies the contact point. For the initial position, the position angles of the contact point are:

$$
\begin{aligned}
& \delta_{P, 1, i n i}=0 \\
& \delta_{P, 2, i n i}=0
\end{aligned} .
$$

Then the $\delta_{1 / 2, \text { ini }}$ of any points of the gears can be obtained by geometrical calculation. 


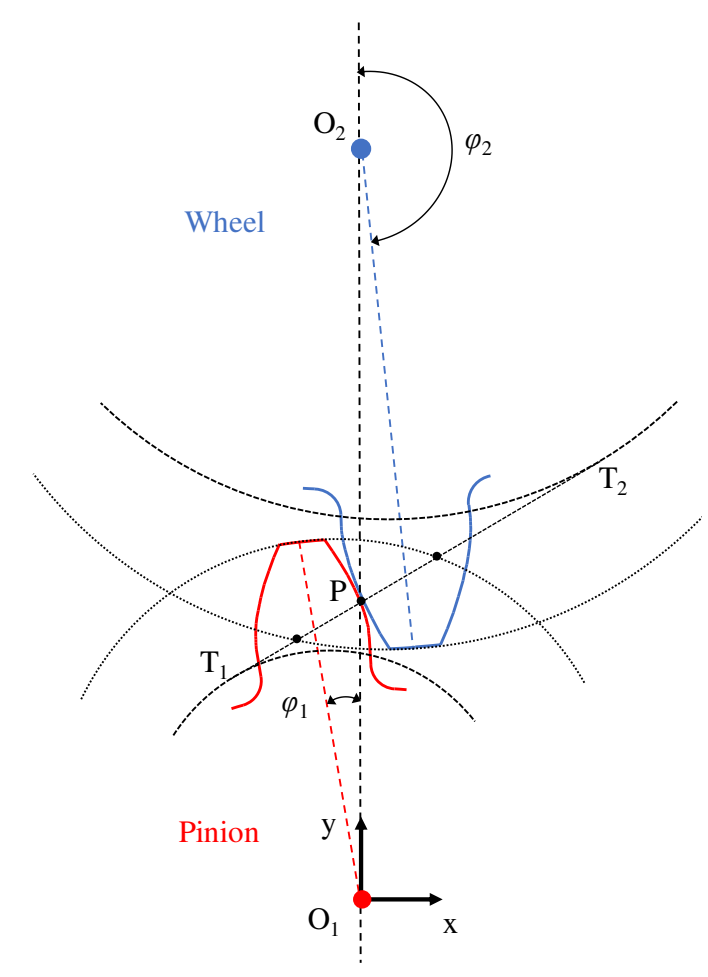

(a) Initial position

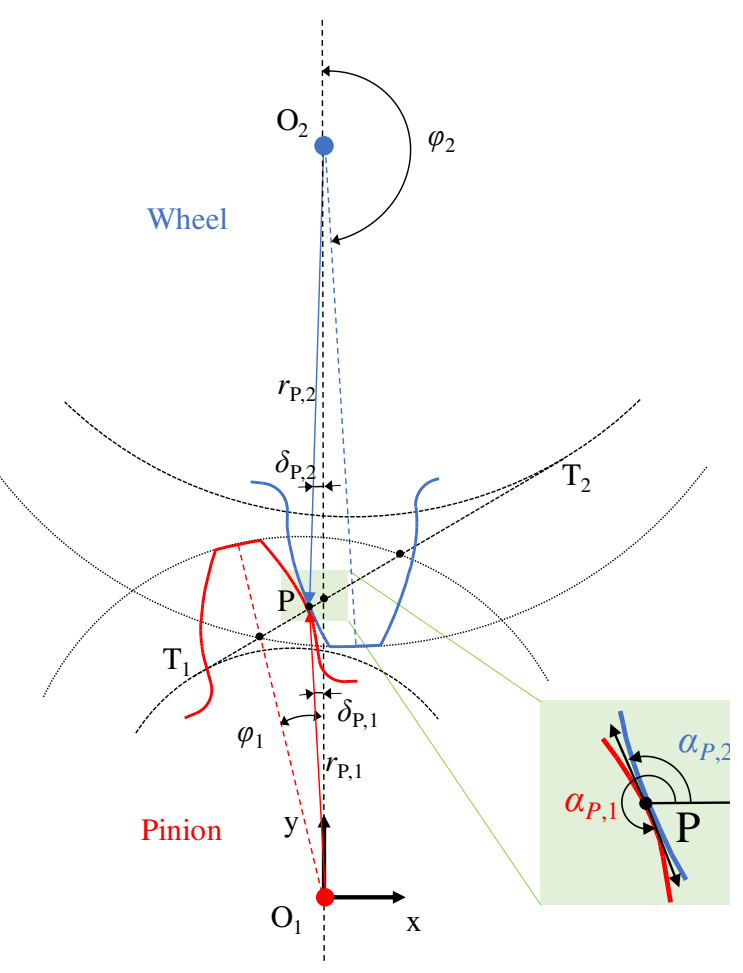

(b) Random position

Fig. 1. Gear pair in (a) initial and (b) random position in the meshing process. P: point of contact. $\varphi$ : rotation angle of the gears

When the pinion is at a random position with a rotation angle $\varphi_{1}$ (Fig. 1 (b)), the conditions are as follows:

$$
\begin{gathered}
{\left[\begin{array}{l}
x_{1} \\
y_{1}
\end{array}\right]=\left[\begin{array}{l}
r_{1}\left(\varphi_{1}\right) \sin \left(\delta_{1}\right) \\
r_{1}\left(\varphi_{1}\right) \cos \left(\delta_{1}\right)
\end{array}\right],} \\
r_{P, 2}=\sqrt{x_{P}^{2}+\left(a-y_{P}\right)^{2}}, \\
\delta_{P, 2}=\arctan \left(\frac{x_{p}}{a-y_{p}}\right), \\
\delta_{1 / 2}-\delta_{1 / 2, \text { ini }}=\varphi_{1 / 2},
\end{gathered}
$$

where $r_{1 / 2}$ are the flank radius of the point and $\alpha$ is the center distance. The position angles $\delta_{1 / 2}$ of any point corresponding to the radius $r_{1 / 2}$ are obtained based on the initial position by geometrical analysis during the meshing process.

According to the gear meshing principle, the normal vectors of the contact points of the gear pair are collinear. As illustrated in Fig. 1, this means

$$
\alpha_{P, 1}-\alpha_{P, 2}= \pm 180^{\circ}
$$

where $\alpha_{P, 1 / 2}$ are the slope angles of the contact point.

Also, for any $\varphi_{1 / 2}$ : 


$$
\begin{aligned}
& \alpha_{1 / 2}\left(\varphi_{1 / 2}\right)-\alpha_{1 / 2, \text { ini }}=\varphi_{1 / 2}, \\
& \alpha_{1 / 2, \text { ini }}=\arctan \left(-\frac{x_{1 / 2}^{\prime}}{y_{1 / 2}^{\prime}}\right),
\end{aligned}
$$

where the prime represents the derivative with respect to time. Thus, the functional relation between $\alpha_{1 / 2}$ and $r_{1 / 2}$ can be established.

The contact point $\mathrm{P}$ is found by the iteration of $r_{P, 1}$ from the tooth root $r_{f}$ to the tooth tip $r_{a}$. When the pinion is at any rotation angle $\varphi_{1}$, the slope angle $\alpha_{P, 1}$ of the hypothetical contact point $\mathrm{P}_{1}$ with the flank radius $r_{P, 1}$ can be obtained by Eq. (7); then, the flank radius $r_{P, 2}$ of the corresponding point $\mathrm{P}_{2}$ in the wheel is obtained by Eq. (3); third, the slope angle $\alpha_{P, 2}$ is obtained; finally, the contact point $\mathrm{P}=\mathrm{P}_{1}=\mathrm{P}_{2}$ will be confirmed if the slope angles $\alpha_{P, 1 / 2}$ satisfy Eq. (6). Otherwise, the next calculation will be conducted. It is found that the contact point is determined by the tooth profile geometry, thus this method can be applied to tooth with tip relief and deformation.

The curvature radius of the contact point (in spite of the effect of tooth deformation, tooth tip relief and wear) can be calculated by

$$
\rho=\left|\frac{\left[\left(x^{\prime}\right)^{2}+\left(y^{\prime}\right)^{2}\right]^{3 / 2}}{x^{\prime} y^{\prime \prime}-y^{\prime} x^{\prime \prime}}\right|,
$$

where the double prime represents the second derivative with respect to time.

The backlash of the gears is given by

$$
L\left(\varphi_{1}\right)=\varphi_{2}-\varphi_{1} \cdot i_{G}
$$

where $i_{G}$ is the transmission ratio.

Moreover, the meshing tooth of the gear pair and the path of contact can be confirmed based on the flank radius $r_{P, 1}$ of contact point $\mathrm{P}$ on the pinion.

\subsection{Tooth deformation at the contact point}

As shown in Fig. 2, tooth deformations include bending $w_{t b}$, shear $w_{t s}$, compression $w_{r}$, and body deformation $w_{t k}$, where black line is the undeformed tooth and blue line is the deformed tooth. The displacement deformations at point $\mathrm{P}$ by these deformations along the normal direction are, respectively

$$
w_{t b}=\int_{r_{f}}^{r_{P}} \int_{r_{f}}^{r} \frac{\cos \alpha_{n}}{E^{\prime}} \frac{F_{u}\left[y\left(r_{P}\right)-y(r)\right]-F_{r} x\left(r_{P}\right)}{l y(r)} d r d r
$$




$$
\begin{gathered}
w_{t s}=\cos \alpha_{n} \int_{r_{f}}^{r_{P}} \tan \left(\frac{\chi F_{u}}{G^{\prime} A(r)}\right) d r, \\
w_{r}=\cos \alpha_{n}\left(\tan \alpha_{n}-v\right) \int_{r_{f}}^{r_{P}} \frac{F_{r}}{E^{\prime} A(r)} d r,
\end{gathered}
$$

where $r$ is the flank radius, $A$ is the section area, $x$ and $y$ represent the coordinates of the load point, $F_{u}$ and $F_{r}$ are the component forces of the normal force along the coordinate axis, and $E^{\prime}, G^{\prime}$, and $\chi$ are the material parameters.

The body deformation [36] is $w_{t k}=w_{K P}+w_{K T}$, where $w_{K P}$ and $w_{K T}$ respectively represent the parallel displacement and tilting rotation of the tooth, are given according to engineering experience:

$$
\begin{gathered}
w_{K P}=\frac{4.8 F_{u}}{E \cdot l_{\text {eff }}}\left[\frac{\left(1-v^{2}\right)}{\pi}\left(1+0.294 \tan ^{2} \alpha_{n}\right)\right], \\
w_{K T}=\frac{2 F_{u}}{E \cdot l_{e f f}}\left[\frac{9\left(1-v^{2}\right)}{\pi} \frac{y\left(r_{P}\right)-x\left(r_{P}\right) \tan \alpha_{n}-y\left(r_{f}\right)}{2 x\left(r_{f}\right)}+(1+v)(1-2 v)\left(\frac{y\left(r_{P}\right)-x_{P} \tan \alpha_{n}-y\left(r_{f}\right)}{2 x_{f}}\right)\right],
\end{gathered}
$$

where $E$ and $v$ are the material parameters, and $l_{\text {eff }}$ is the effective tooth width.

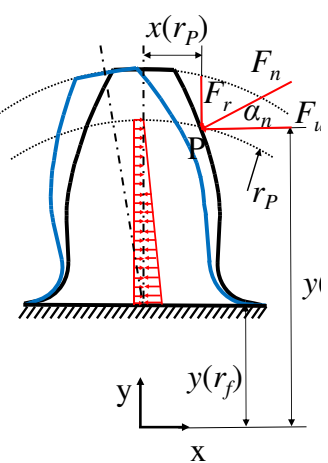

(a) Bending

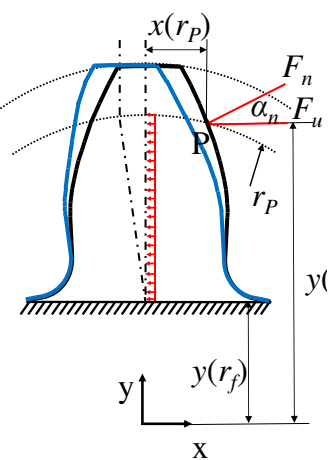

(b) Shear

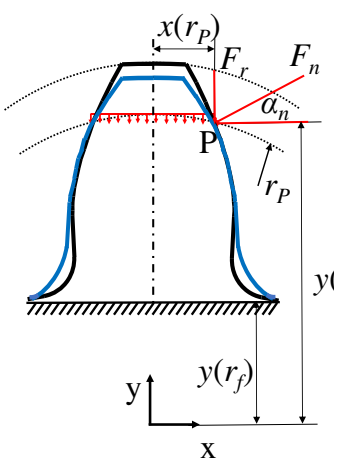

(c) Compression

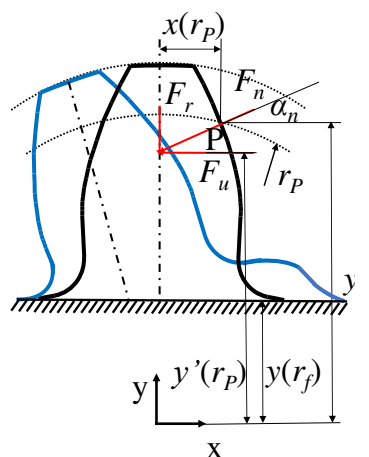

(d) Body deformation

Fig. 2. The tooth deformations by load $F_{n}$ applied at point $P$.

Therefore, the deformation angle of $\mathrm{P}$ is

$$
w_{P}=\frac{\left[w_{t b}+w_{t s}+w_{r}+w_{t k}\right] \cos \alpha_{n}}{r_{P}}
$$

Moreover, the local Hertz contact deformation will appear at the contact point by the load, as shown in Fig. 3. The local displacement deformations along the contact line of the gears are

$$
w_{H, 1 / 2}=2 \frac{F_{n}}{l_{\text {eff }}} \frac{1-v^{2}}{E^{\prime} \pi}\left[\ln \left(\frac{2 h_{1 / 2}}{b_{H}}\right)-\frac{v}{2(1-v)}\right],
$$


where $F_{n}$ is the meshing force, $h_{1 / 2}$ are the depths of force, and $b_{H}$ is the half contact width

$$
b_{H}=\sqrt{\frac{8 F_{n}\left(1-v^{2}\right) \rho_{P, 1} \rho_{P, 2}}{\pi l_{e f f} E^{\prime}\left(\rho_{P, 1}+\rho_{P, 2}\right)}} .
$$

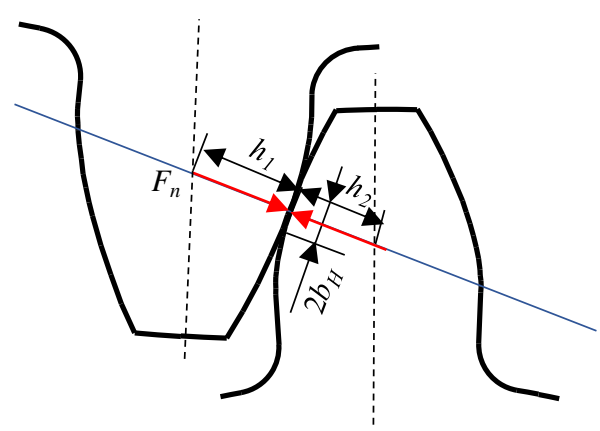

Fig. 3. Local Hertz contact deformation due to meshing force $F_{n} . b_{H}$ : half contact width. $h_{1 / 2}$ : depth of force.

Based on Eqs. (16) and (17), the tooth deformation and local Hertz contact deformation contribute to the actual deformation of the profile at the contact point during the gear meshing process. The comprehensive deformation of the meshing tooth at the contact point by the load $F_{n}$ is

$$
W=\frac{w_{P, 1}}{\cos \alpha_{n}} \cdot\left(-i_{G}\right)+\frac{w_{P, 2}}{\cos \alpha_{n}}+\frac{w_{H, 1} \cos \alpha_{n}}{r_{P, 1}} \cdot\left(-i_{G}\right)+\frac{w_{H, 2} \cos \alpha_{n}}{r_{P, 2}} .
$$

Therefore, $F_{n}$ and $W$ are related by Eq. (19) when the pinion is at a rotation angle of $\varphi_{1}$. it is noted that the comprehensive tooth deformation $W$ may lead to the double contact as shown in Section 3, which may increase the risk of micro-pitting.

Based on a traversal iteration method for the flank radius $r_{1}$, the theoretical contact points and contact path are confirmed during meshing. However, the contact path of the gear pair will change because of tooth deformation. Furthermore, only when the comprehensive deformation $W$ is larger than the backlash $L$ will the teeth contact each other and the load be transmitted. The Hertz contact stress is

$$
p_{H}=\frac{2}{\pi} \frac{F_{n}}{b_{H} l_{e f f}} .
$$

In this section, meshing simulation of gears with tip relief is conducted considering the actual contact path. The risk of micro-pitting can be discussed according to Hertz contact stress for gears with or without tip relief.

\section{Equations for tooth tip relief}

\subsection{Effects of linear tip relief}

On the tooth flank, $\mathbf{A}$ and $\mathbf{E}$ are the positions of engaging-in and out, $\mathbf{B}$ and $\mathbf{D}$ are the transition positions of single and 
double-tooth contact, and $\mathbf{C}$ is the pitch point. In this study, the tooth tips of both pinion and wheel are modified with a tip relief amount of $170 \mu \mathrm{m}$ and start position of $\mathbf{D}$ on the tooth flank. But note that the discussions in this paper are conducted based on the pinion.

Based on the gear meshing process in Section 2, Fig. 4 discusses the effects of linear tip relief on the curvature radius and Hertz contact stress along the contact path, where profile deviation is the distance between the actual and involute tooth profile along the meshing line. As shown in Fig. 4 (a), serious Hertz contact stress peaks occur at $\mathbf{A}$ and $\mathbf{E}$ on the tooth flank without tooth tip relief. This is because tooth deformation causes meshing interference between the tooth tip of the wheel and the tooth root of the pinion when the gear pair starts meshing. Moreover, it is also found that double contact by tooth deformation occurs at the tooth root according to the path of contact, increasing the risk of micro-pitting. As shown in Fig. 4 (b), after linear tip relief, the Hertz contact stress peaks are reduced by $56.3 \%$ and $60.9 \%$ at $\mathbf{A}$ and $\mathbf{E}$, respectively, because the removed material of the tooth tip mitigates the mesh interference. Moreover, mitigating double contact of the tooth root also decreases the risk of micro-pitting. However, the Hertz contact stress peaks increase significantly at $\mathbf{B}$ and $\mathbf{D}$ by $21.6 \%$ and $13.4 \%$, respectively, which would result in the initiation of micro-pitting at the transition area between the tip relief region and the involute profile. It is evident that the sharp decrease in the curvature radius at point $\mathbf{D}$ causes stress peaks. In summary, micro-pitting is reduced at $\mathbf{A}$ and $\mathbf{E}$ but increased at $\mathbf{B}$ and $\mathbf{D}$ by linear tip relief. 

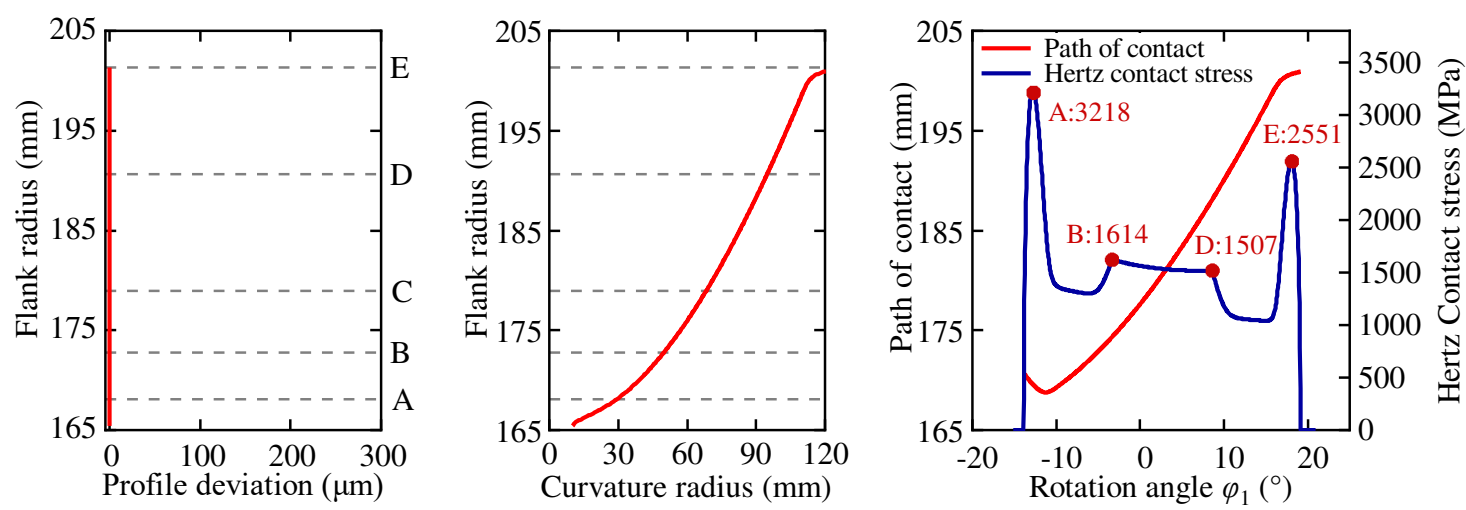

(a) Without tip relief
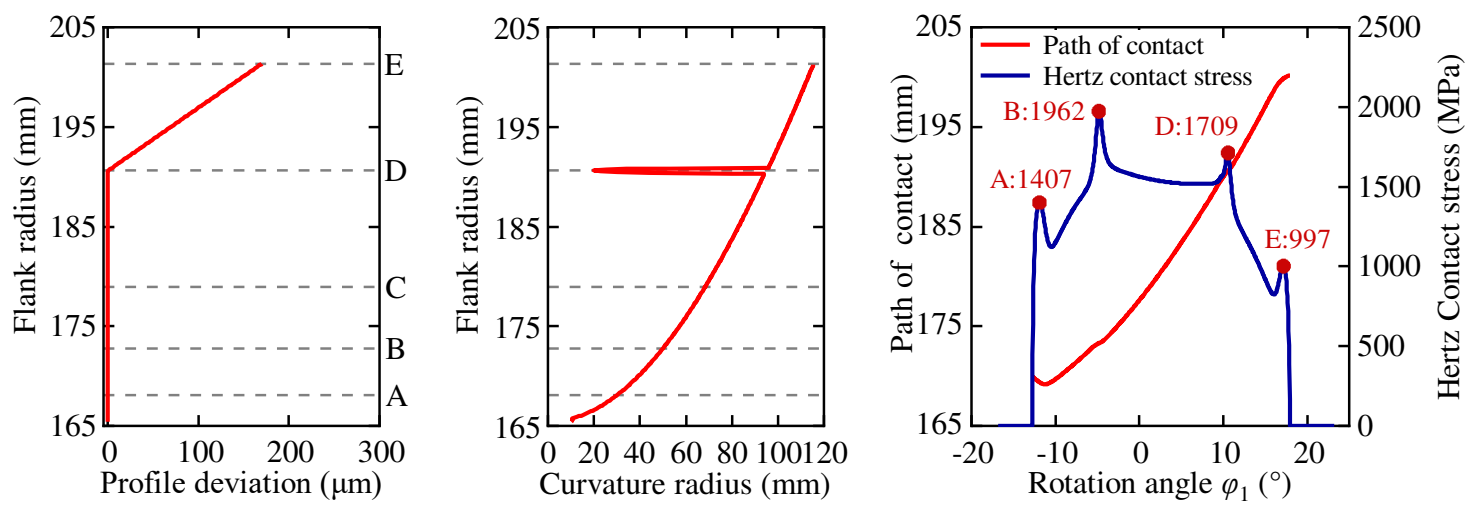

(b) Linear tip relief

Fig. 4. Profile deviation, curvature radius, and Hertz contact stress (a) without tip relief and (b) with linear tip relief

\subsection{Equation for arctangent-proportional tip relief}

In order to reduce the stress peaks at the transition areas between the tip relief region and the involute profile while retaining the advantages of linear tip relief, the arctangent-proportional tip relief is proposed in this paper for a smoother transition and illustrated in Fig. 5. The governing equation for the method is

$$
\Delta_{s, 1}\left(X_{a}\right)=C_{a} \cdot\left(\frac{X_{a}}{C_{l}}\right) \cdot \frac{\arctan \left[c \cdot\left(X_{a} / C_{l}\right)^{2}\right]}{\arctan (c)},
$$

where $\Delta_{s, 1}$ represents the profile deviation by arctangent-proportional tip relief, $X_{a}$ is the height coordinate of the arctangent-proportional tip relief with the range from $0 \mathrm{~mm}$ to $C_{l}, C_{a}$ is the size of the tooth tip relief, and $c$ is a constant coefficient. 


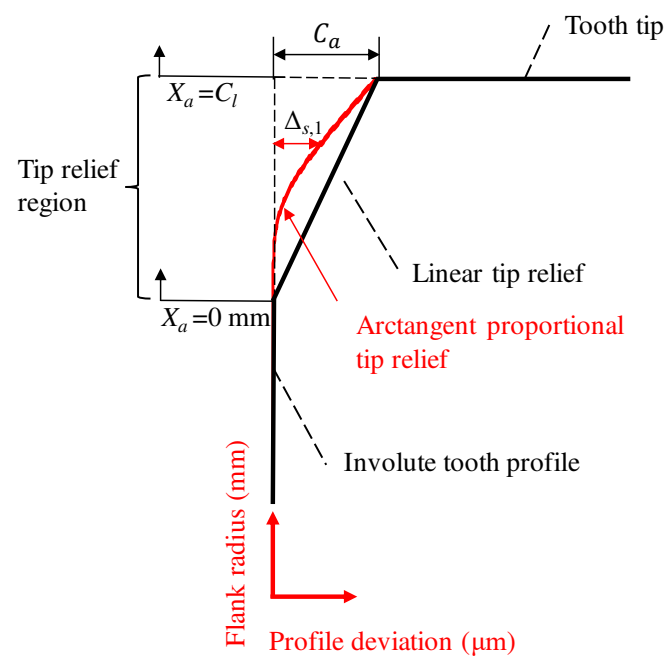

Fig. 5. Flank radius versus profile deviation in arctangent-proportional tip relief

Fig. 6 illustrates the profile deviation, curvature radius and Hertz contact stress along the contact path with arctangentproportional tip relief, where 50,5 and 0.5 are selected as representative large, moderate, and small values of $c$, respectively. As shown in Fig. 6 (a), the arctangent-proportional tip relief achieves a smoother transition at $\mathbf{D}$. Thus, the Hertz contact stress peaks at transition areas $\mathbf{B}$ and $\mathbf{D}$ are reduced by $6.7 \%$ and $9.1 \%$ for $c=50$, respectively, compared with those obtained by linear tip relief. Fig. 6 (b) shows that for $c$ is 5 , the tooth flank at $\mathbf{D}$ is smoother with a larger curvature radius. The Hertz contact stress peaks at $\mathbf{B}$ and $\mathbf{D}$ are reduced by $15.1 \%$ and $10.7 \%$, respectively, compared with those obtained by linear tip relief. However, as shown in Fig. 6 (c), a smaller $c$ leads to larger Hertz contact stresses in the tip relief region with little reduction in the Hertz contact stress at transition areas. Actually, the arctangentproportional tip relief with smaller $c$ is similar to the parabolic tip relief, which would produce less removed material at the tip relief region causing serious micro-pitting. As a result, a moderate $c$ reaches an agreement about the Hertz contact stresses at the transition areas $\mathbf{B}$ and $\mathbf{D}$ and the tooth tip region. However, the Hertz contact stress peaks at $\mathbf{A}$ and $\mathbf{E}$ and the double contact due to tooth deformation at the tooth root are still predominant, promoting the initiation and propagation of micro-pitting. 

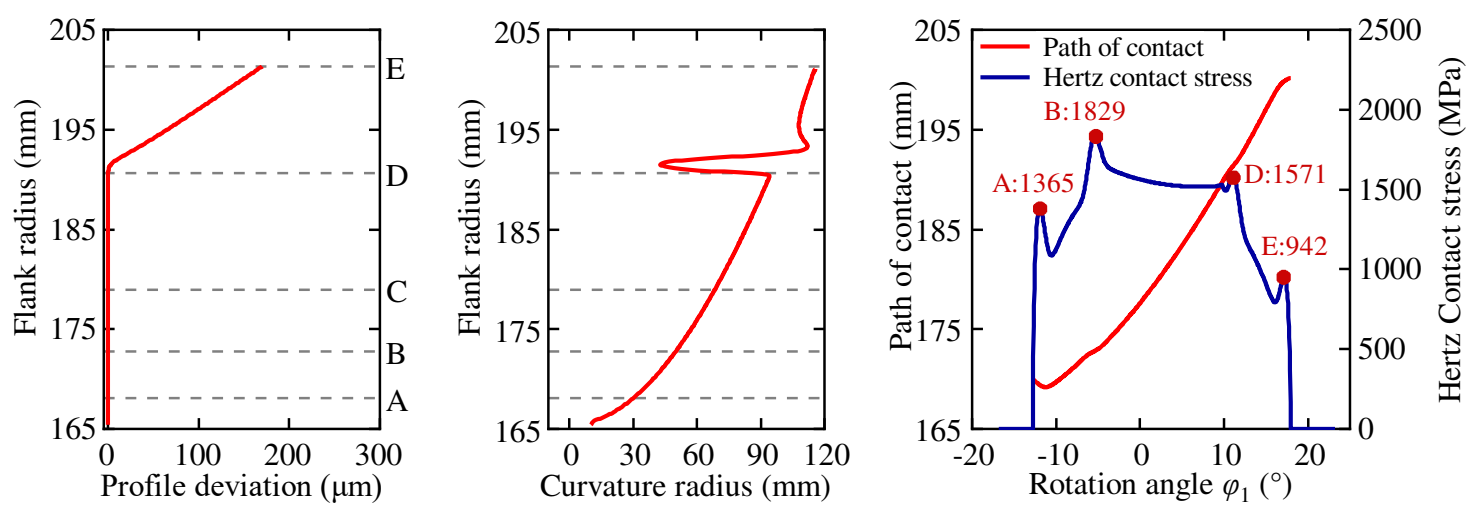

(a) Arctangent-proportional tip relief with $c=50$.
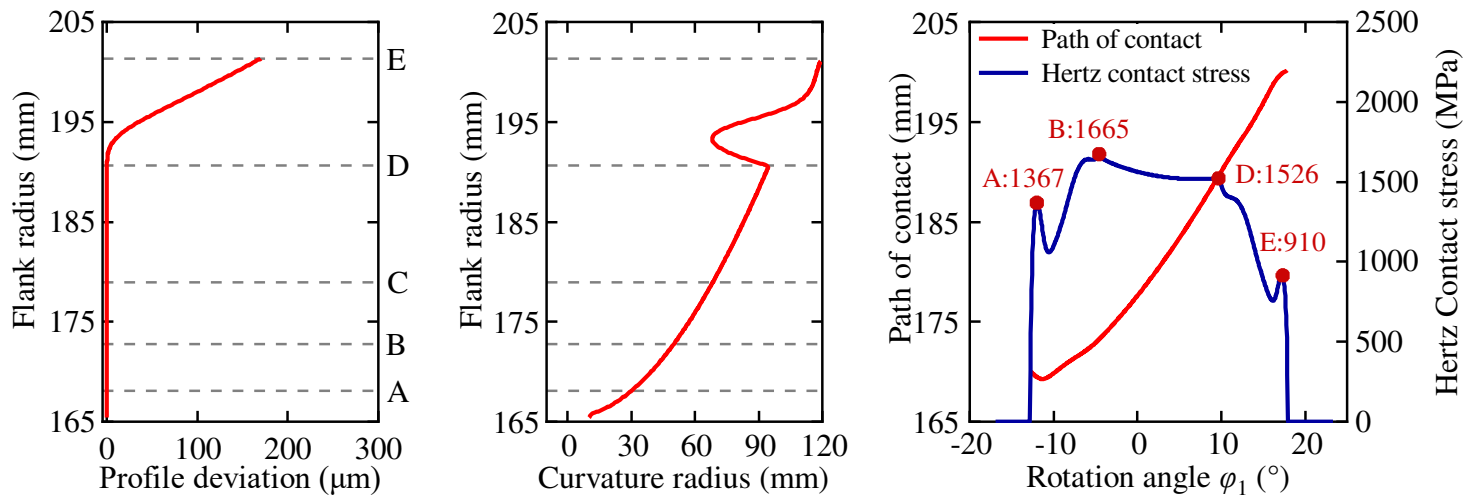

(b) Arctangent-proportional tip relief with $c=5$.
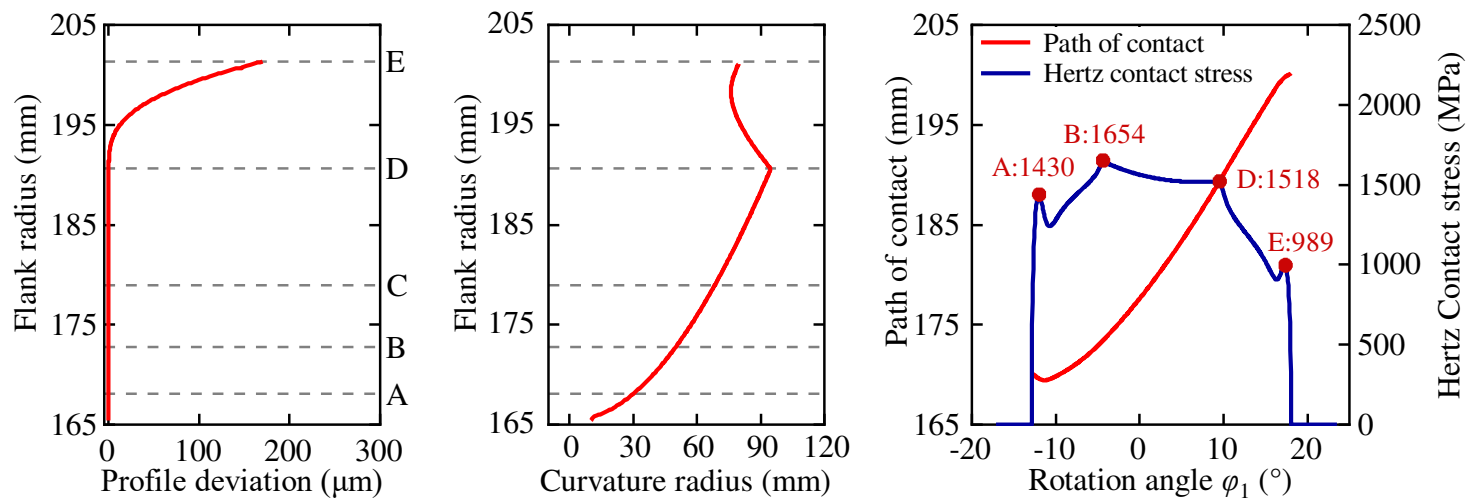

(c) Arctangent-proportional tip relief with $c=0.5$.

Fig. 6. The effects on the tooth meshing of arctangent-proportional tip relief with different $c$

\subsection{Equation for the progressive fillet}

To reduce double contact of the tooth root and the Hertz contact stress peaks at the transition area between the tip relief region and the tooth tip by the arctangent-proportional tip relief, a progressive fillet is further proposed based on the arctangent-proportional tip relief for a smoother transition, as shown in Fig. 7: 


$$
\Delta_{s, 2}\left(X_{b}\right)=\frac{X_{b}}{r_{k}} \cdot\left(r_{k}-\sqrt{r_{k}^{2}-X_{b}^{2}}\right)
$$

where $\Delta_{s, 2}$ represents the profile deviation by progressive fillet, $X_{b}$ is the height coordinate of the progressive fillet with the range from $0 \mathrm{~mm}$ to $l_{r}, r_{k}$ is the radius of the progressive fillet.

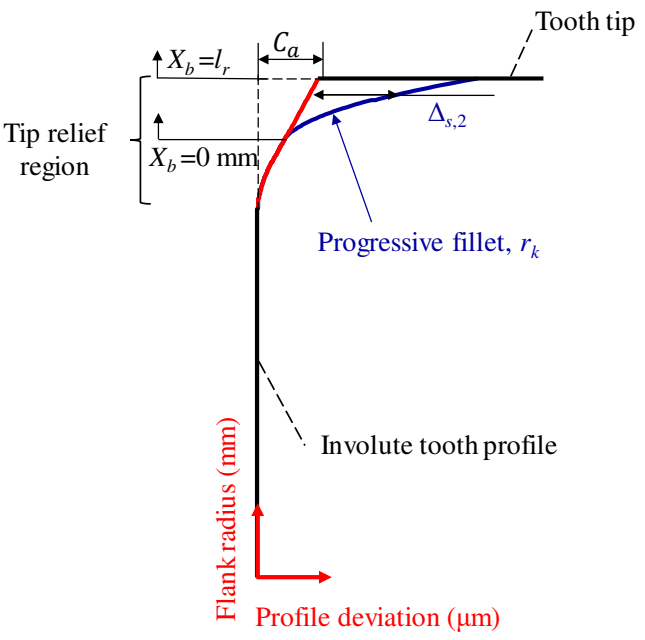

Fig. 7. Flank radius versus profile deviation in the progressive fillet

Fig. 8 shows the effects of the geometrical parameter $r_{k}$ of the progressive fillet on the curvature radius, Hertz contact stress and path of contact. As shown in Fig. 8 (a), the reductions of the Hertz contact stress at $\mathbf{A}$ and $\mathbf{E}$ and of the double contact are limited for $r_{k}=m_{n} / 3$, where $m_{n}$ is normal modulus. This is because the curvature radius at the transition area between the tooth tip and tip relief region is too small. Furthermore, as shown by the profile deviation, the sudden change of the profile curve at the start position of the progressive fillet would increase the risk of micro-pitting there. Fig. 8 (b) shows that when $r_{k}$ is increased to $m_{n} / 2$, the Hertz contact stress peaks at $\mathbf{A}$ and $\mathbf{E}$ and the contact path are ameliorated compared with those shown in Fig. 8 (a). The tooth flank is smoother at the start position of the progressive fillet with a larger curvature radius. As shown in Fig. 8 (c), the Hertz contact stress peaks at $\mathbf{A}$ and $\mathbf{E}$ and the double contact of the tooth root are eliminated with $r_{k}=m_{n}$. Fig. 8 indicates that a larger $r_{k}$ produces a greater reduction in the Hertz contact stress and double contact, suggesting a lower risk of micro-pitting. However, excessive $r_{k}$ is not recommended despite this trend because it will result in too little material of the tooth tip, leading to a significant decrease in the strength. Therefore, $r_{k}=m_{n}$ is recommended in this study for minimizing the risk of micro-pitting. 

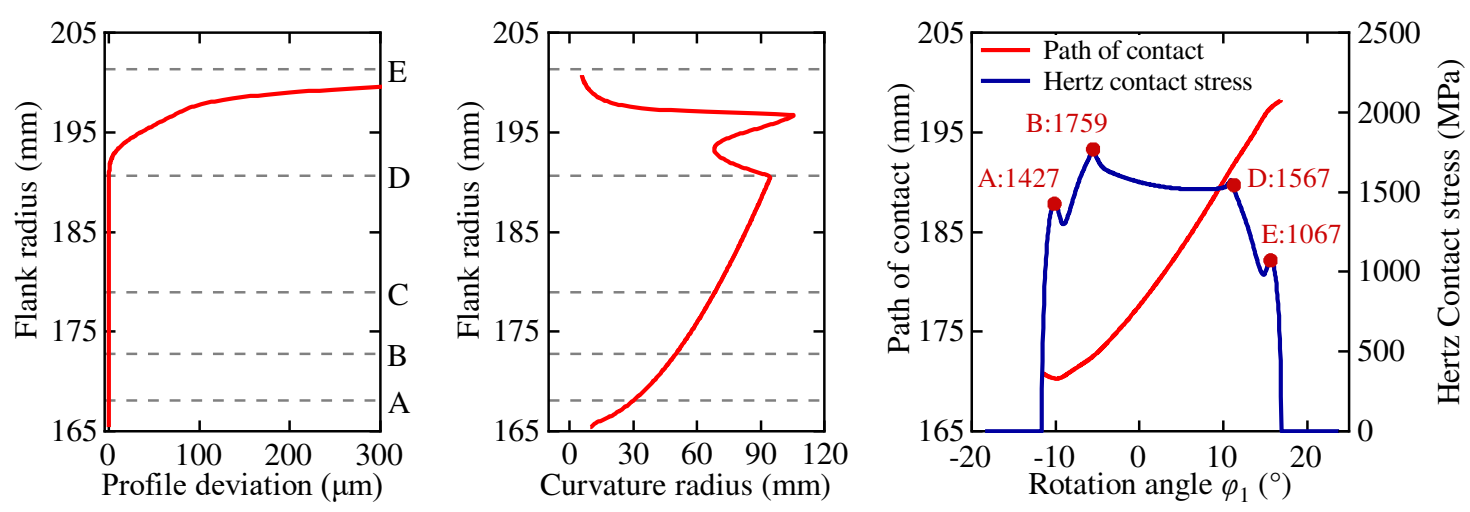

(a) $r_{k}=m_{n} / 3$
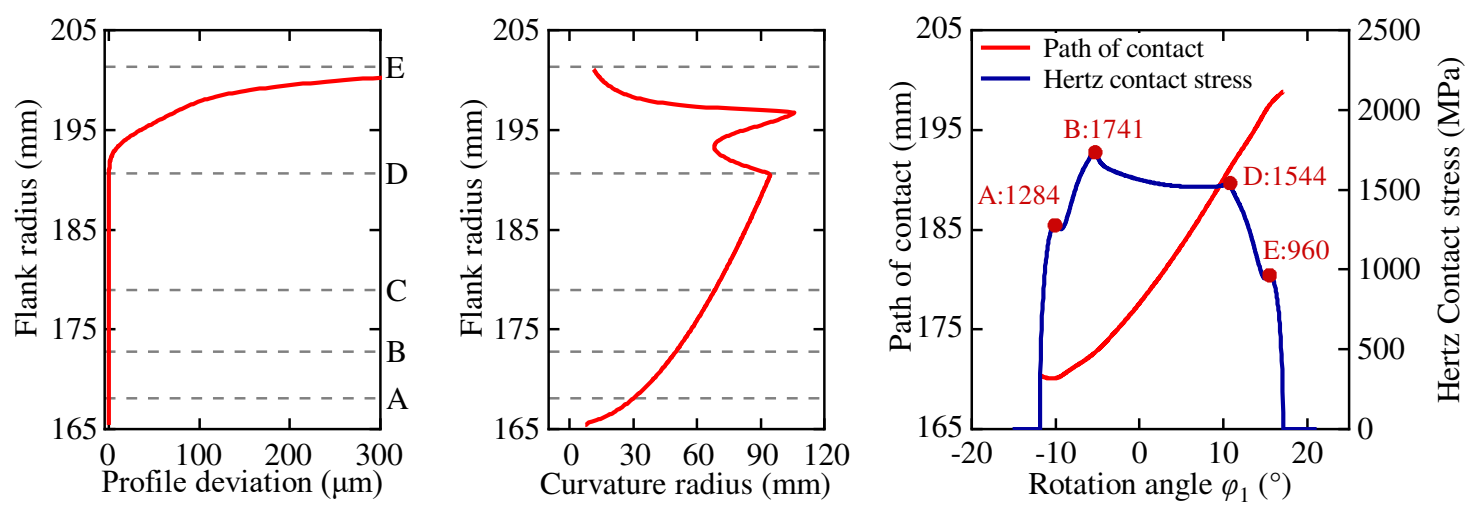

(b) $r_{k}=m_{n} / 2$
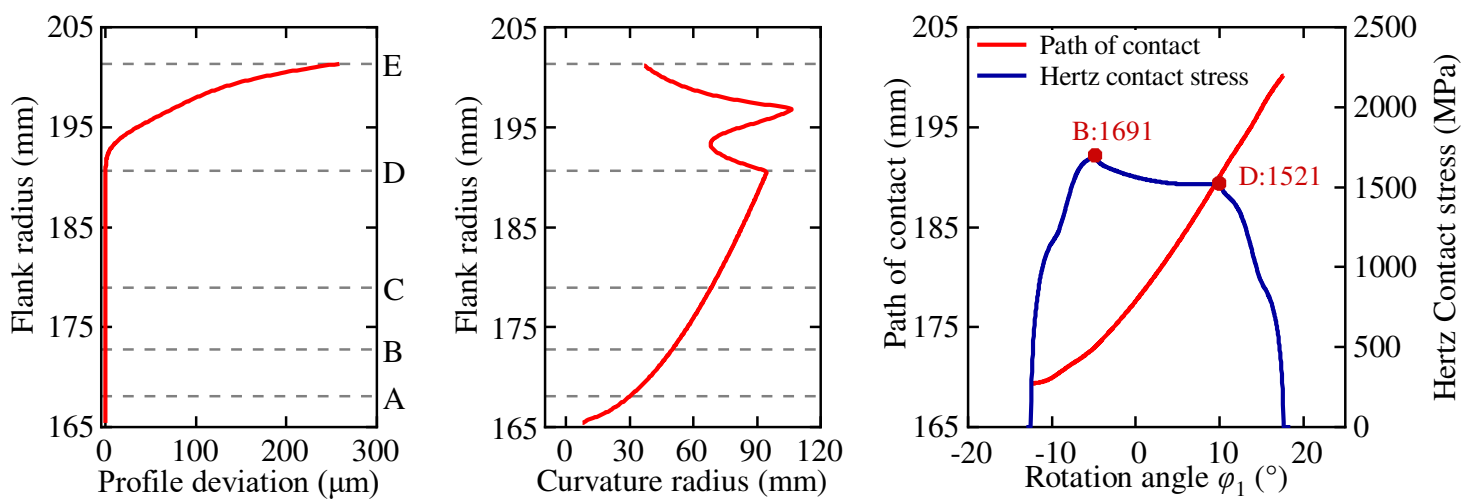

(c) $r_{k}=m_{n}$

Fig. 8. The effects on the tooth meshing by the progressive fillet with different geometrical parameters $r_{k}$

\section{Simulation verifications and bench tests}

\subsection{Wear simulation results}

The feathers of micro-pitting are the micro-pits on the tooth surface. Therefore, micro-pitting has been evaluated by surface wear in previous studies $[24,25]$ and it is demonstrated effective. Cracks causes surface wear but short cracks are 
discussed in this paper because only they lead to micro-pitting. Based on the Dang Van multiaxial fatigue criterion [37] and the fretting fatigue crack initiation theory [38], Xu et al. proposed a crack criterion model [10] to predict the crack initiation. The limiting value of the criterion was $R_{\mathrm{S}}=1$, indicating the initiation of the first cracks on the tooth flank surface. The risk of micro-pitting increases when $R_{\mathrm{S}}<1$; thus, the crack criterion value $R_{\mathrm{S}}$ can also be a safety factor for the tooth flank surface.

The crack criterion is used to predict the initiation of the first crack, regardless of the number of loading cycles. In practice, with an increase in the number of loading cycles, new cracks initiate, and cracks on the tooth flank surface will increase and expand in depth. Besides, surface roughness $R a$, sliding velocity $v_{s}$, rolling velocity $v_{r}$, surface hardness $H_{s}$ and minimum film thickness $h_{\min }$ all affect the wear rate. Based on an empirical formula for calculating tooth surface fatigue wear [38], Xu et al. proposed a wear rate model [10] including the crack density

$$
\frac{d V}{d N}=k_{s} \cdot k_{w} \cdot\left(\frac{p_{H}}{p_{H, R}}\right)^{\alpha} \cdot\left(\frac{\left|v_{s}\right|}{\left|v_{r}\right|}\right)^{\beta} \cdot\left[1-\left(\frac{R a_{\Sigma}}{R a_{\Sigma, R}}\right)^{\kappa} \cdot \frac{v_{s}}{v_{r}}\right]^{\chi} \cdot\left(\frac{R a_{\Sigma}}{h_{\text {min }}}\right)^{\gamma} \cdot\left(\frac{H_{s}}{H_{s, R}}\right)^{\delta} \cdot \frac{1}{N_{R}}+\frac{c d_{R}}{N_{R}} \cdot[\arctan (\zeta \cdot c d)]^{\varepsilon},
$$

where $k_{s}$ and $k_{w}$ are the parameters determined by lubricant and material properties; the subscript $R$ denotes the reference value as listed in ref. [10]; $R a_{\Sigma}$ represents the arithmetic mean center roughness by $R a_{\Sigma}=\left(R a_{1}+R a_{2}\right) / 2 ; N_{R}$ is the reference number of load cycle as $10^{6} ; \mathrm{d} V / \mathrm{d} N$ is the wear ratein $\mu \mathrm{m} / 10^{6}$ load cycle; and $\alpha, \beta, \gamma, \delta, \varepsilon, \zeta, \kappa$, and $\chi$ are coefficients determined by experiment. It is noted that the parameters about meshing conditions can be obtained by meshing simulation in Section 2.

Thus, the amount of wear after $\Delta N_{\mathrm{k}}$ cycles is

$$
V_{k}=\left(\frac{d V}{d N}\right)_{k} \cdot \Delta N_{k}
$$

where the wear amounts are calculated for the profile deviation to evaluate the micro-pitting. Moreover, the wear simulation is carried out based on the newest tooth profile, contact path and load distribution after certain cycles. This is because too much calculation time is needed if the wear simulation is conducted after every cycle, and the simulation results are unauthentic when all calculations are based on the initial tooth profile. Therefore, the wear can be simulated under different conditions including running-in for micro-pitting.

A spur gear pair was chosen for verifying the tooth tip relief method proposed in this paper. The basic gear and the tooth tip relief parameters are listed in Table 1, and the lubricant parameters are listed in Table 2. 


\begin{tabular}{llll}
\hline \multirow{2}{*}{ Parameter } & & Value & \\
\cline { 2 - 3 } & & Pinion & Wheel \\
\hline Tooth number & $z$ & 16 & 24 \\
Tip diameter & $d_{a}$ & $402.69 \mathrm{~mm}$ & $507.62 \mathrm{~mm}$ \\
Profile shift coefficient & $x$ & 0.1817 & 0.1715 \\
Center distance & $a$ & $447.33 \mathrm{~mm}$ & \\
Normal modulus & $m_{n}$ & $22 \mathrm{~mm}$ & \\
Tooth width & $b$ & $100 \mathrm{~mm}$ & \\
Normal pressure angle & $\alpha_{n}$ & $20^{\circ}$ & \\
Average roughness & $R_{a}$ & $1 \mu \mathrm{m}$ & \\
amount of tooth tip relief & $C_{a}$ & $170 \mu \mathrm{m}$ & \\
starting positions of the progressive fillet & $l_{r}$ & $m_{n} / 5$ & \\
radius of progressive fillet & $r_{k}$ & $m_{n}$ & \\
Surface hardness & $H V_{s}$ & $760 \mathrm{HV}$ \\
Core hardness & $H V_{c}$ & $353 \mathrm{HV}$ & \\
\hline
\end{tabular}

Table 2 lubricant parameters

\begin{tabular}{lll}
\hline Parameter & & Value \\
\hline Oil type & - & Mineral oil \\
Density of lubricant & $\rho_{15}$ & $907 \mathrm{~kg} / \mathrm{m}^{3}$ \\
Lubricate temperature & $\theta_{\text {oil }}$ & $90^{\circ} \mathrm{C}$ \\
Kinematic viscosity & $v \theta$ & $213.7 \mathrm{~mm}^{2} / \mathrm{s}$ at $40^{\circ} \mathrm{C} ; 18.29 \mathrm{~mm}^{2} / \mathrm{s}$ at $100^{\circ} \mathrm{C}$
\end{tabular}

Simulation results of a load-stage test according to FVA 54 [39] for both linear tip relief and arctangent-proportional tip relief with a progressive fillet are presented in Fig. 9. The results for the crack criterion $R_{S}$ show that micro-pitting is concentrated in the area from $\mathbf{A}$ to $\mathbf{C}$. However, it would also occur at point $\mathbf{D}$ with more cycles by the linear tip relief, owing to the smaller $R_{S}$ there. The maximum and submaximal profile deviations due to the linear tip relief are $12 \mu \mathrm{m}$ and $7 \mu \mathrm{m}$, respectively, whereas the maximum profile deviations due to the novel tooth tip relief are only $3 \mu \mathrm{m}$. Compared with linear tip relief, this novel tooth tip relief method eliminates the most serious wear at B. Fig. 9 illustrates that the 
arctangent-proportional tip relief and the progressive fillet reduce both the initiation and propagation of cracks effectively, indicating a significant reduction in micro-pitting. This is because the proposed tooth tip relief method can reduce the Hertz contact stress peaks and double contact in the gear meshing process. Moreover, based on the results in Section 3, it is found that the arctangent-proportional tip relief and the progressive fillet reduce the maximum and submaximal profile wear, respectively. In addition, with the process of gear meshing cycles, this novel method achieves less wear with higher quality of the tooth surface; thus, the factor of safety is further improved and the micro-pitting on the tooth flank is further reduced.
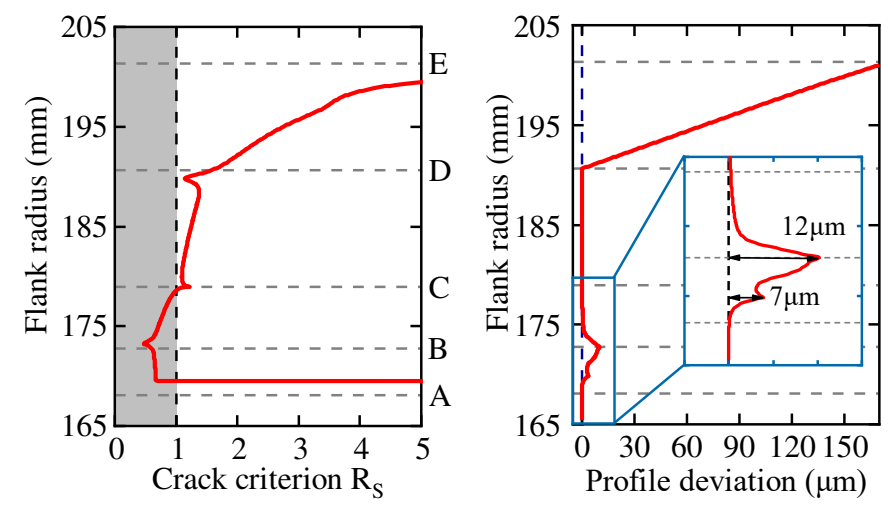

(a) Linear tip relief
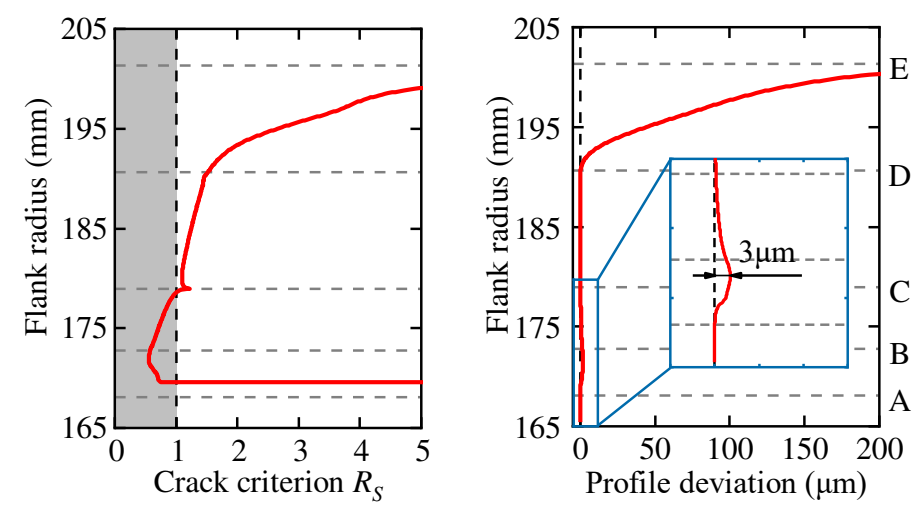

(b) Arctangent-proportional tip relief with a progressive fillet

Fig. 9. Effects on micro-pitting of (a) linear tip relief and (b) arctangent-proportional tip relief with a progressive fillet

\subsection{Test results}

The bench tests were carried out by a back-to-back gearbox test rig designed by Ruhr-Universität Bochum. A touchprobe system was applied to measure the roughness of the gear-flank surface. Parameters of test gear pair are the same with Table 1 , and the material is of chemical composition $18 \mathrm{CrNiMo} 7-6$. The modified gears were manufactured using a grinding-wheel dresser with the quality of five. The lubricant is mineral oil with the property in Table 2. 
The procedure of tests was according to the load stage test as specified in FVA 54 [39]. The procedure contains six steps. In each load stage, the Hertz contact stress at the pitch point should be guaranteed as the specified value by FVA 54 [39]. The running time of the 1-5 load stage is about $16 \mathrm{~h}$ with the pinion revolutions of 2.1 million, but the time of running-in stage is $1 \mathrm{~h}$ with the pinion revolutions of 0.13 million. Moreover, the circumferential velocity is set as $8.3 \mathrm{~m} / \mathrm{s}$. The detailed operation conditions of each load test stage are followed as Table 3.

Table 3 Operation conditions of each load test stage

\begin{tabular}{llll}
\hline Load stage & $\begin{array}{l}\text { Hertz contact stress at } \\
\text { the pitch point }\end{array}$ & Toque on pinion & Pinion speed \\
\hline Running-in & $795.1 \mathrm{MPa}$ & $11,675 \mathrm{Nm}$ & $442.7 \mathrm{rpm}$ \\
$\mathbf{1}$ & $945.1 \mathrm{MPa}$ & $16,487 \mathrm{Nm}$ & $442.7 \mathrm{rpm}$ \\
$\mathbf{2}$ & $1093.9 \mathrm{MPa}$ & $22,098 \mathrm{Nm}$ & $442.7 \mathrm{rpm}$ \\
$\mathbf{3}$ & $1244.9 \mathrm{MPa}$ & $28,616 \mathrm{Nm}$ & $442.7 \mathrm{rpm}$ \\
$\mathbf{4}$ & $1395.4 \mathrm{MPa}$ & $35,931 \mathrm{Nm}$ & $442.7 \mathrm{rpm}$ \\
$\mathbf{5}$ & $1547.3 \mathrm{MPa}$ & $44,197 \mathrm{Nm}$ & $442.7 \mathrm{rpm}$ \\
\hline
\end{tabular}

Fig. 10 shows the measured profile deviations with the proposed tooth tip relief method and the linear tooth tip relief after the loading tests. The measured profile consistent with the simulation results is displayed in Fig. 10. In particular, as shown in Fig. 10 (b), the tooth surface is kept intact and surface damage is avoided as much as possible. Moreover, there is a good agreement between the simulation in Fig. 9 and the experiments in Fig. 10 for the profile deviation. In addition, the pictures in Fig. 10 are the tooth surfaces after bench tests and the areas surrounded by red frame are the most worn areas. It is obvious that the surface wear area is reduced significantly with this novel method compared with that by linear tip relief. By comparing the profile deviations and pictures in Fig. 10, it can be concluded that the level of micropitting in the tooth flank is minimized and that the proposed tooth tip relief is valid. 


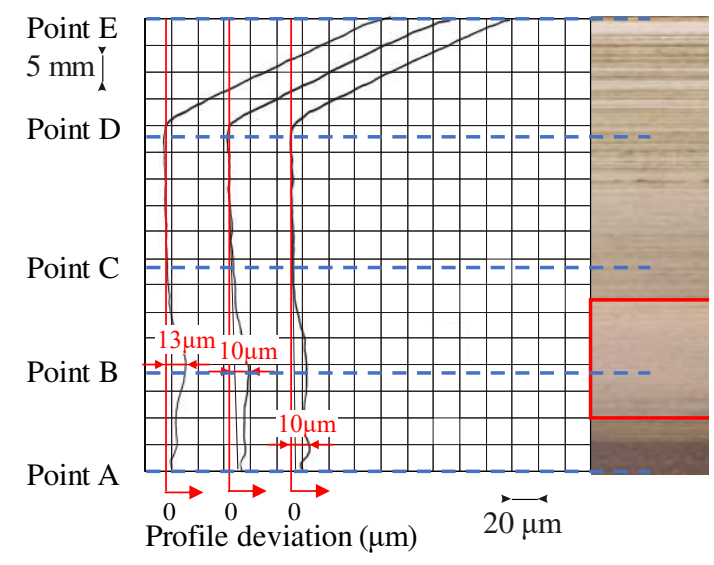

(a) The linear tip relief

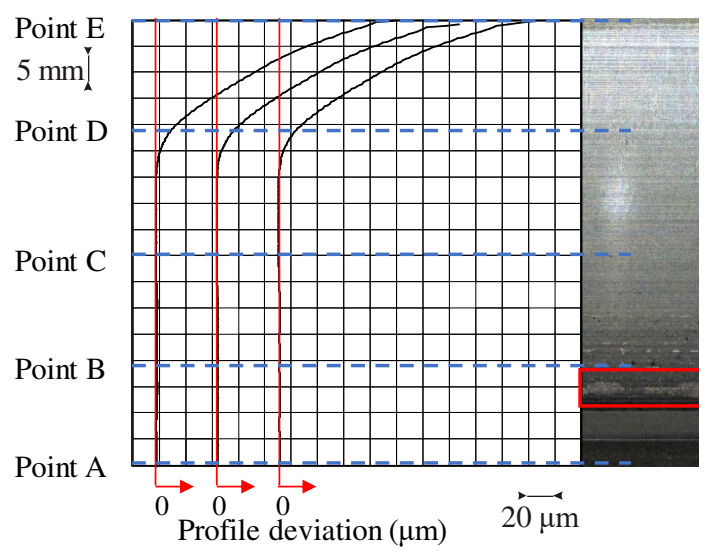

(b) The arctangent-proportional tip relief with a

Fig. 10. Bench test results of profile deviation after tooth tip relief

\section{Conclusion}

Considering both tooth deformation and tooth tip relief, this study first develops a gear meshing simulation model. The gear contact path, curvature radius, and local Hertz contact stress can be calculated considering the actual contact path despite the tooth tip relief and tooth deformation. In order to eliminate the stress peaks in the transition areas of the tooth flank and thus reduce the micro-pitting of spur gears, arctangent-proportional tip relief and progressive fillet are proposed. The effects of the key parameters of the tip relief on the gear contact path, curvature radius and Hertz contact stress are discussed, then the recommended parameters are given. Theoretical simulations and bench tests are carried out to verify the effectiveness of the proposed novel tooth tip relief method in reducing the micro-pitting of the tooth flank. The following conclusions are drawn from this study:

(1) Linear tip relief leads to the reduction of stress peaks at $\mathbf{A}$ and $\mathbf{E}$, but a significant increase in those at $\mathbf{B}$ and $\mathbf{D}$, causing serious micro-pitting. Moreover, micro-pitting would occur at $\mathbf{D}$ after more cycles.

(2) Arctangent-proportional tip relief achieves a smooth transition between the tip relief region and the involute profile. Furthermore, the Hertz contact stresses at $\mathbf{B}$ and $\mathbf{D}$ are reduced more with the recommended parameter value $c=5$.

(3) Progressive fillet reduces the Hertz contact stress peaks at $\mathbf{A}$ and $\mathbf{E}$ by the smooth transition between the tip relief region and the tooth tip, and the key parameter $r_{k}=m_{n}$ is recommended. And it can eliminate the double contact of tooth root for further reduction of micro-pitting.

(4) According to the theoretical wear model and bench tests, this novel tooth tip relief method reduces micro-pitting significantly compared with linear tip relief. Furthermore, the arctangent-proportional tip relief and the progressive fillet 
reduce the maximum and submaximal micro-pitting, respectively.

With this tooth tip relief method, the stress distribution is improved and micro-pitting phenomena in the tooth flank of spur gears is reduced considerably. Moreover, this proposed tip relief method can be achieved by grinding wheel dressers. Therefore, the tooth tip relief method proposed in this paper can be used in engineering practice to improve gear stability by reducing micro-pitting.

\section{Authors' Contributions}

$\mathrm{XX}$ and PD were in charge of the whole trial; YL and SZ finished the modeling, data analysis and wrote the manuscript; YL assisted with the manuscript checking; SW and ZW reviewed and edited the manuscript. All authors read and approved the final manuscript.

\section{Authors' Information}

Xiangyang Xu, born in 1965 , is a is currently a professor and a PhD candidate supervisor at School of Transportation Science and Engineering, Beihang University, China. He received his PhD degree from Harbin Institute of Technology, China, in 1999. His research interests at vehicle automatic transmission theory and control technology, and presided over the development of the world's first front-drive 8-speed automatic transmission (8AT) and its series products.

Yinghua Liang, born in 1985, is currently a $\mathrm{PhD}$ candidate at School of Transportation Science and Engineering, Beihang University, China.

Shumiao Zuo, born in 1997, is currently a PhD candidate at School of Transportation Science and Engineering, Beihang University, China.

Peng Dong, born in 1985, is currently an associate professor at School of Transportation Science and Engineering, Beihang University, China. He received his PhD degree from Ruhr University of Bochum, Germany, in 2015. His research interests at transmission system reliability.

Yanfang Liu, born in 1978, is currently an associate professor at School of Transportation Science and Engineering, Beihang University, China. He received his PhD degree from Beihang University, China, in 2006.

Shuhan Wang, born in 1979, is currently a professor at School of Transportation Science and Engineering, Beihang University, China. He received his PhD degree from Beihang University, China, in 2009.

Zhuo Wang, is currently a director at Machining and Assembly Research Room, State Key Laboratory of Smart Manufacturing for Special Vehicles and Transmission System, China. 


\section{Competing Interests}

The authors declare that they have no competing interests.

\section{Funding}

Supported by the National Natural Science Foundation of China (Grant Number: 51705012 and 52072018), Key Science and Technology Innovation Project of Shandong Province (Grant Number: 2019JZZY010913 and 2020CXGC011004) and Key Science and Technology Project of Guangxi Province (Grant Number: AA19254013).

\section{Acknowledgments}

The authors acknowledge the support of Beijing Key Laboratory for High-efficient Power Transmission and System Control of New Energy Resource Vehicle and the support of the Fundamental Research Funds for the Central Universities.

\section{References}

[1] Luo, Y., Baddour, N., \& Liang, M. (2019). Dynamical modeling and experimental validation for tooth pitting and spalling in spur gears. Mechanical Systems and Signal Processing, 119, 155-181. doi:10.1016/j.ymssp.2018.09.027

[2] Kundu, P., Darpe, A. K., \& Kulkarni, M. S. (2019). A correlation coefficient based vibration indicator for detecting natural pitting progression in spur gears. Mechanical Systems and Signal Processing, 129, 741-763. doi:10.1016/j.ymssp.2019.04.058

[3] Dong, P., Zuo, S., Du, S., Tenberge, P., Wang, S., Xu, X., \& Wang, X. (2020). Optimum design of the tooth root profile for improving bending capacity. Mechanism and Machine Theory, 151. doi:10.1016/j.mechmachtheory.2020.103910

[4] Feng, G., Xie, Z., \& Zhou, M. (2019). Geometric design and analysis of face-gear drive with involute helical pinion. Mechanism and Machine Theory, 134, 169-196. doi:10.1016/j.mechmachtheory.2018.12.020

[5] Wang, W., Liu, H., Zhu, C., Du, X., \& Tang, J. (2019). Effect of the residual stress on contact fatigue of a wind turbine carburized gear with multiaxial fatigue criteria. International Journal of Mechanical Sciences, 151, 263-273. doi:10.1016/j.ijmecsci.2018.11.013

[6] Roy, S., White, D., \& Sundararajan, S. (2018). Correlation between evolution of surface roughness parameters and micropitting of carburized steel under boundary lubrication condition. Surface and Coatings Technology, 350, 445452. doi:10.1016/j.surfcoat.2018.05.083 
[7] Wang, W., Liu, H., Zhu, C., Wei, P., \& Tang, J. (2019). Effects of microstructure on rolling contact fatigue of a wind turbine gear based on crystal plasticity modeling. International Journal of Fatigue, 120, 73-86. doi:10.1016/j.ijfatigue.2018.10.022

[8] Wang, W., Liu, H., Zhu, C., Wei, P., \& Wu, W. (2019). Micromechanical analysis of gear fatigue-ratcheting damage considering the phase state and inclusion. Tribology International, 136, 182-195. doi:10.1016/j.triboint.2019.03.040

[9] Wei, P., Zhou, H., Liu, H., Zhu, C., Wang, W., \& Deng, G. (2019). Modeling of contact fatigue damage behavior of a wind turbine carburized gear considering its mechanical properties and microstructure gradients. International Journal of Mechanical Sciences, 156, 283-296. doi:10.1016/j.ijmecsci.2019.04.004

[10] Xu, X., Lai, J., Lohmann, C., Tenberge, P., Weibring, M., \& Dong, P. (2019). A model to predict initiation and propagation of micro-pitting on tooth flanks of spur gears. International Journal of Fatigue, 122, 106-115. doi:10.1016/j.ijfatigue.2019.01.004

[11] Vrček, A., Hultqvist, T., Baubet, Y., Marklund, P., \& Larsson, R. (2019). Micro-pitting Damage of Bearing Steel Surfaces under Mixed Lubrication Conditions: Effects of Roughness, Hardness and ZDDP Additive. Tribology International, 138, 239-249. doi:10.1016/j.triboint.2019.05.038

[12] Zhang, B., Liu, H., Zhu, C., \& Li, Z. (2019). Numerical simulation of competing mechanism between pitting and micro-pitting of a wind turbine gear considering surface roughness. Engineering Failure Analysis, 104, 1-12. doi:10.1016/j.engfailanal.2019.05.01

[13] Morales-Espejel, G. E., Rycerz, P., \& Kadiric, A. (2018). Prediction of micropitting damage in gear teeth contacts considering the concurrent effects of surface fatigue and mild wear. Wear, 398-399, 99-115. doi:10.1016/j.wear.2017.11.016

[14] Li, S., \& Kolivand, A. (2020). On the dynamics of a lubricated roller contact. Mechanism and Machine Theory, 153. doi:10.1016/j.mechmachtheory.2020.103959

[15] Moorthy, V., \& Shaw, B. A. (2013). An observation on the initiation of micro-pitting damage in as-ground and coated gears during contact fatigue. Wear, 297(1), 878-884. doi:10.1016/j.wear.2012.11.001

[16] Zhang, B., Xiu, M., Tan, Y. T., Wei, J., \& Wang, P. (2019). Pitting corrosion of SLM Inconel 718 sample under surface and heat treatments. Applied Surface Science, 490, 556-567. doi:10.1016/j.apsusc.2019.06.043 
[17] Cen, H., Morina, A., \& Neville, A. (2018). Effect of slide to roll ratio on the micropitting behaviour in rolling-sliding contacts lubricated with ZDDP-containing lubricants. Tribology International, 122, 210-217. doi:10.1016/j.triboint.2018.02.038

[18] Roy, S., Ooi, G. T. C., \& Sundararajan, S. (2018). Effect of retained austenite on micropitting behavior of carburized AISI 8620 steel under boundary lubrication. Materialia, 3, 192-201. doi:10.1016/j.mtla.2018.08.029

[19] Qin, H., Ren, Z., Zhao, J., Ye, C., Doll, G. L., \& Dong, Y. (2017). Effects of ultrasonic nanocrystal surface modification on the wear and micropitting behavior of bearing steel in boundary lubricated steel-steel contacts. Wear, 392-393, 29-38. doi:10.1016/j.wear.2017.09.012

[20] Krantz, T., Cooper, C., Townsend, D., \& Hansen, B. (2004). Increased Surface Fatigue Lives of Spur Gears by Application of a Coating. Journal of Mechanical Design, 126(6), 1047-1054. doi:https://doi.org/10.1115/1.1799651

[21] Singh, H., Ramirez, G., Eryilmaz, O., Greco, A., Doll, G., \& Erdemir, A. (2016). Fatigue resistant carbon coatings for rolling/sliding contacts. Tribology International, 98, 172-178. doi:10.1016/j.triboint.2016.02.008

[22] Mahmoudi, B., Doll, G. L., Hager, C. H., \& Evans, R. D. (2016). Influence of a WC/a-C:H tribological coating on micropitting wear of bearing steel. Wear, 350-351, 107-115. doi:10.1016/j.wear.2016.01.010

[23] Ochoa, E. d. 1. G., Otero, J. E., Tanarro, E. C., Munoz-Guijosa, J. M., López, B. d. R., \& Cordero, C. A. (2015). Analysis of the effect of different types of additives added to a low viscosity polyalphaolefin base on micropitting. Wear, 322-323, 238-250. doi:10.1016/j.wear.2014.11.014

[24] Cheng, W., Cheng, H. S., Mura, T., \& Keer, L. M. (1994). Micromechanics Modeling of Crack Initiation under Contact Fatigue. Journal of Tribology, 116, 2-8. doi:10.1115/1.2927042

[25] Sellgren, U., Björklund, S., \& Andersson, S. (2003). A finite element-based model of normal contact between rough surfaces. Wear, 254(11), 1180-1188. doi:10.1016/s0043-1648(03)00332-6

[26] Lohmann, C., Walkowiak, M., \& Tenberge, P. (2014). Optimal modifications on helical gears for good load distribution and minimal wear. In International Gear Conference 2014: 26th-28th August 2014, Lyon (pp. 43-54).

[27] Huangfu, Y., Chen, K., Ma, H., Li, X., Han, H., \& Zhao, Z. (2020). Meshing and dynamic characteristics analysis of spalled gear systems: A theoretical and experimental study. Mechanical Systems and Signal Processing, 139. doi:10.1016/j.ymssp.2020.106640

[28] Predki, W., Nazifi, K., \& Lutzig, G. (2011). Micropitting of Big Gearboxes: Influence of Flank Modification and Surface Roughness. 
[29] Simon, V. (1989). Optimal Tooth Modifications for Spur and Helical Gears. Journal of Mechanisms, Transmissions, and Automation in Design, 111(4), 611-615. doi:10.1115/1.3259044

[30] Ni, G., Zhu, C., Song, C., Du, X., \& Zhou, Y. (2017). Tooth contact analysis of crossed beveloid gear transmission with parabolic modification. Mechanism and Machine Theory, 113, 40-52. doi:10.1016/j.mechmachtheory.2017.03.004

[31] Ni, G., Zhu, C., Song, C., Shi, J., \& Liu, S. (2018). Effects of rack-cutter parabolic modification on loaded contact characteristics for crossed beveloid gears with misalignments. International Journal of Mechanical Sciences, 141, 359-371. doi:10.1016/j.ijmecsci.2018.04.003

[32] Lin, H. H., Oswald, F. B., \& Townsend, D. P. (1994). Dynamic loading of spur gears with linear or parabolic tooth profile modifications. Mechanism and Machine Theory, 29(8), 1115-1129. doi:10.1016/0094-114X(94)90003-5

[33] İmrek, H., \& Düzcükoğlu, H. (2007). Relation between wear and tooth width modification in spur gears. Wear, 262(3-4), 390-394. doi:10.1016/j.wear.2006.06.004

[34] Mao, K. (2007). Gear tooth contact analysis and its application in the reduction of fatigue wear. Wear, 262(11-12), 1281-1288. doi:10.1016/j.wear.2006.06.019

[35] Bruyere, J., Velex, P., Guilbert, B., \& Houser, D. R. (2019). An analytical study on the combination of profile relief and lead crown minimizing transmission error in narrow-faced helical gears. Mechanism and Machine Theory, 136, 224-243. doi:10.1016/j.mechmachtheory.2019.03.005

[36] Weber, C., \& Banaschek, K. (1955) . Formänderung und Profilrücknahme bei gerad- ud schrägverzahnten Rädern, 2. Auflage, Vieweg Verlag, Braunschweig.

[37] Dang-Van, K. , Griveau, B. , \& Message, O. . (1982). On a New Multiaxial Fatigue Limit Criterion: Theory and Application.

[38] Ruiz, C., \& Chen, K. C. (1986). LIFE ASSESSMENT OF DOVETAIL JOINTS BETWEEN BLADES AND DISCS IN AERO-ENGINES. I Mech E Conference Publications (Institution of Mechanical Engineers), 1, 187-194.

[39] FVA Information Sheet 54/7. Test procedure for the investigation of micropitting capacity of gear lubricants, 1993. 
Figures

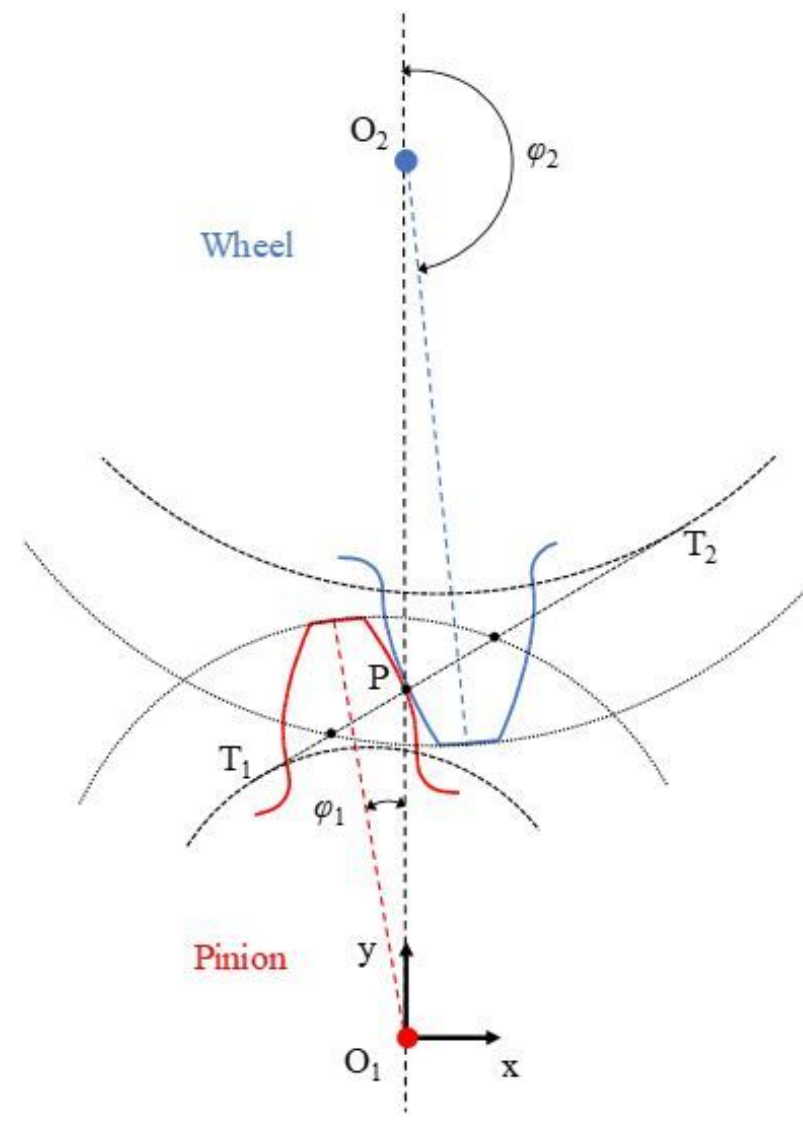

(a) Initial position

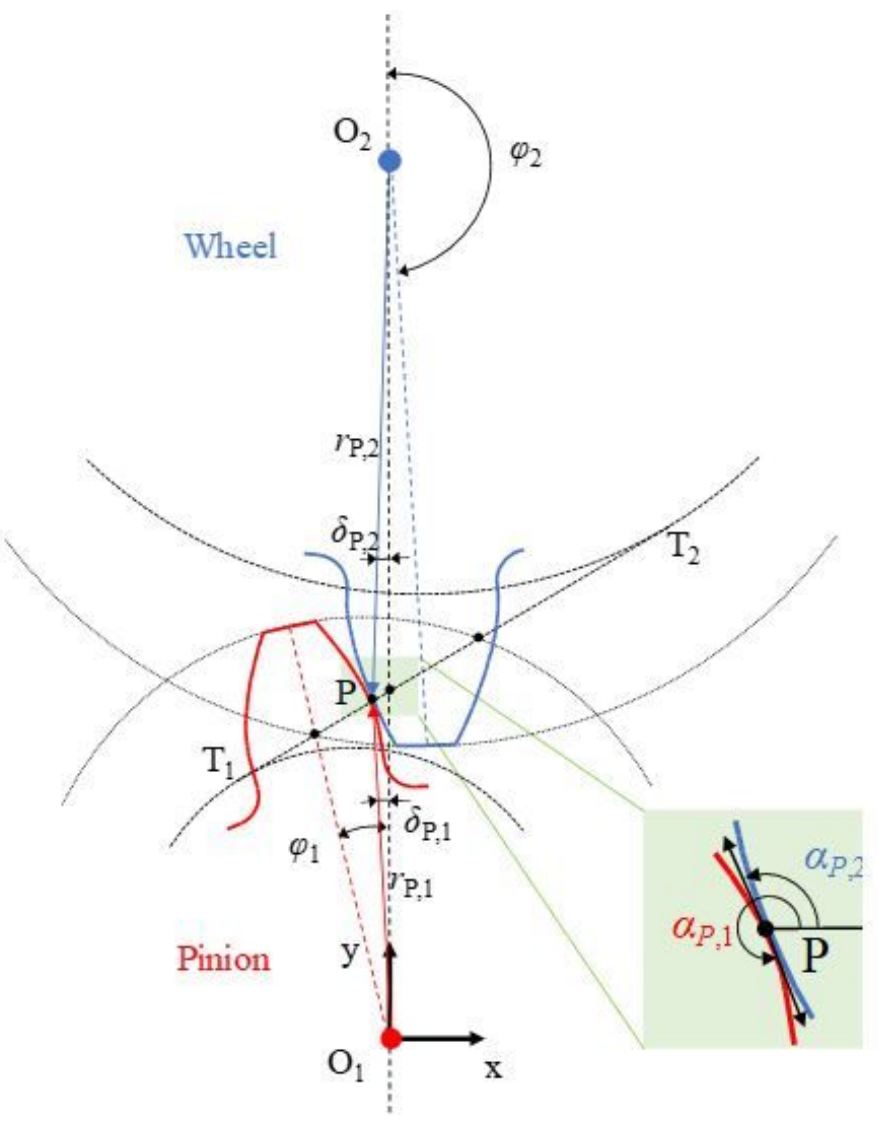

(b) Random position

\section{Figure 1}

Gear pair in (a) initial and (b) random position in the meshing process. P: point of contact. $\varphi$ : rotation angle of the gears 


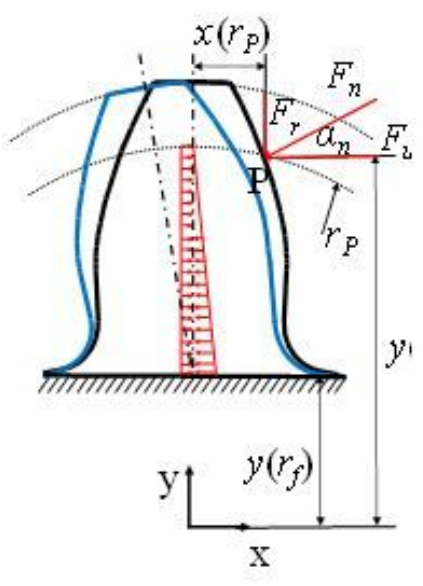

(a) Bending

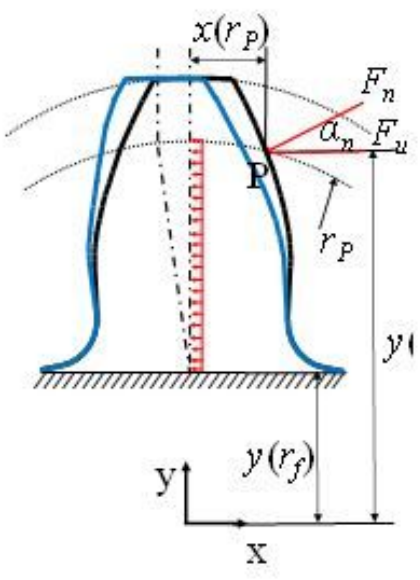

(b) Shear

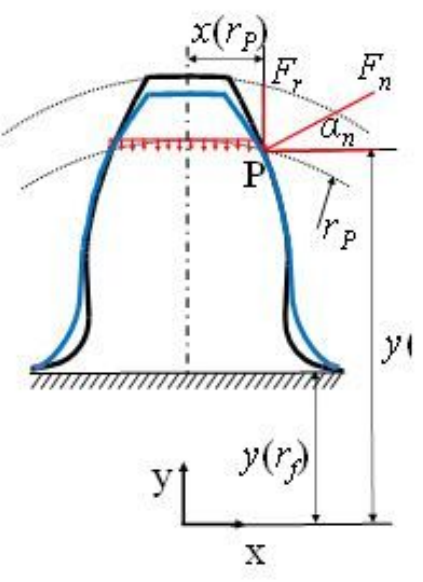

(c) Compression

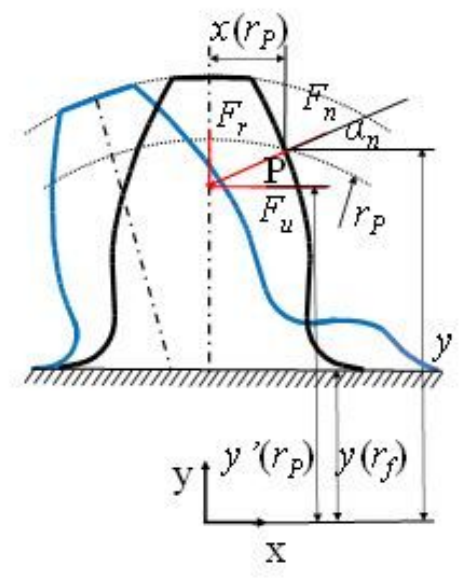

(d) Body deformation

Figure 2

The tooth deformations by load Fn applied at point P.

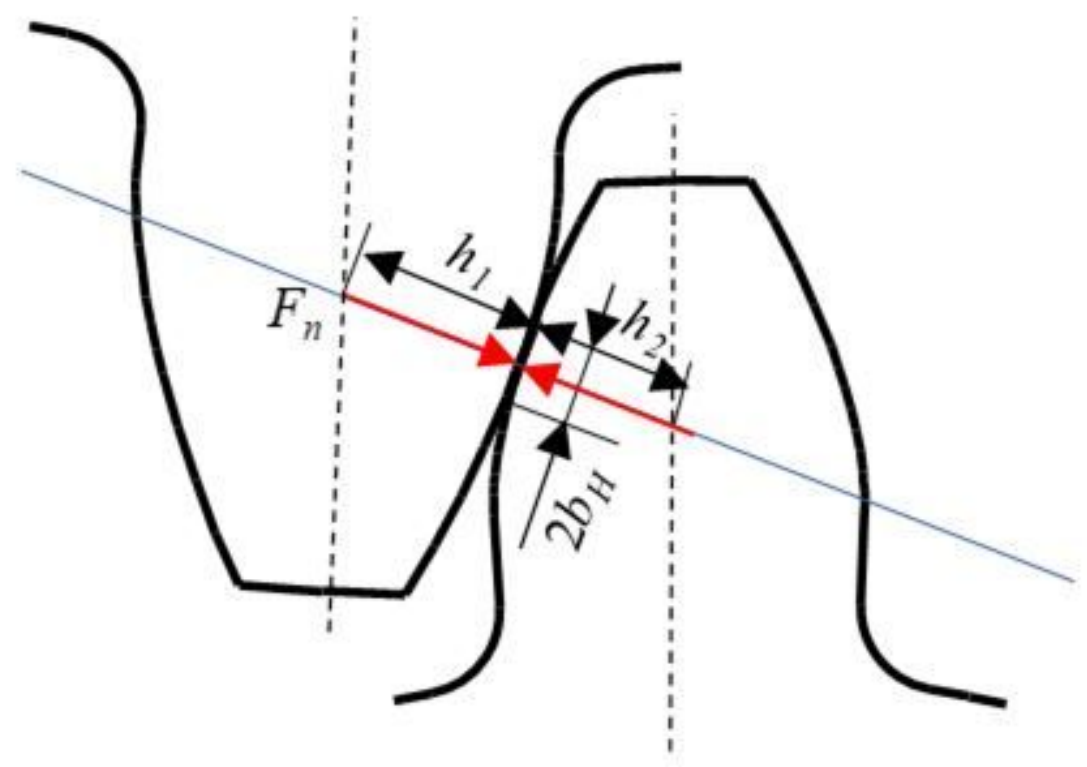

Figure 3

Local Hertz contact deformation due to meshing force Fn. bH: half contact width. h1/2: depth of force. 

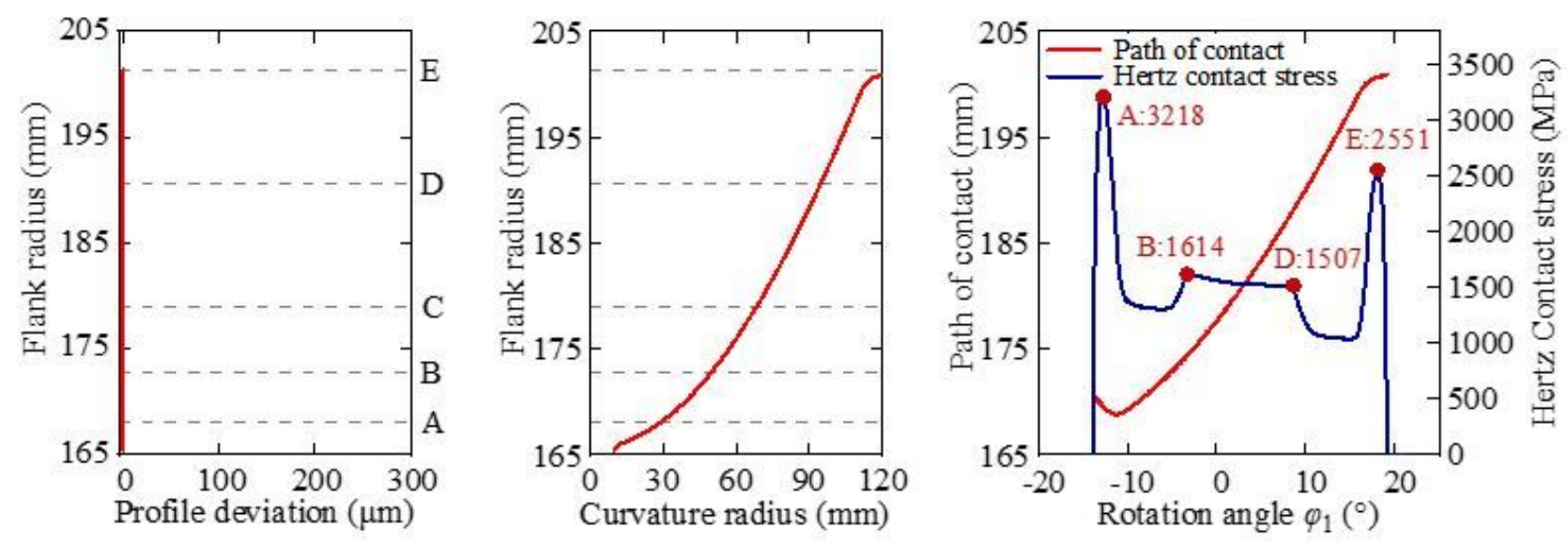

(a) Without tip relief
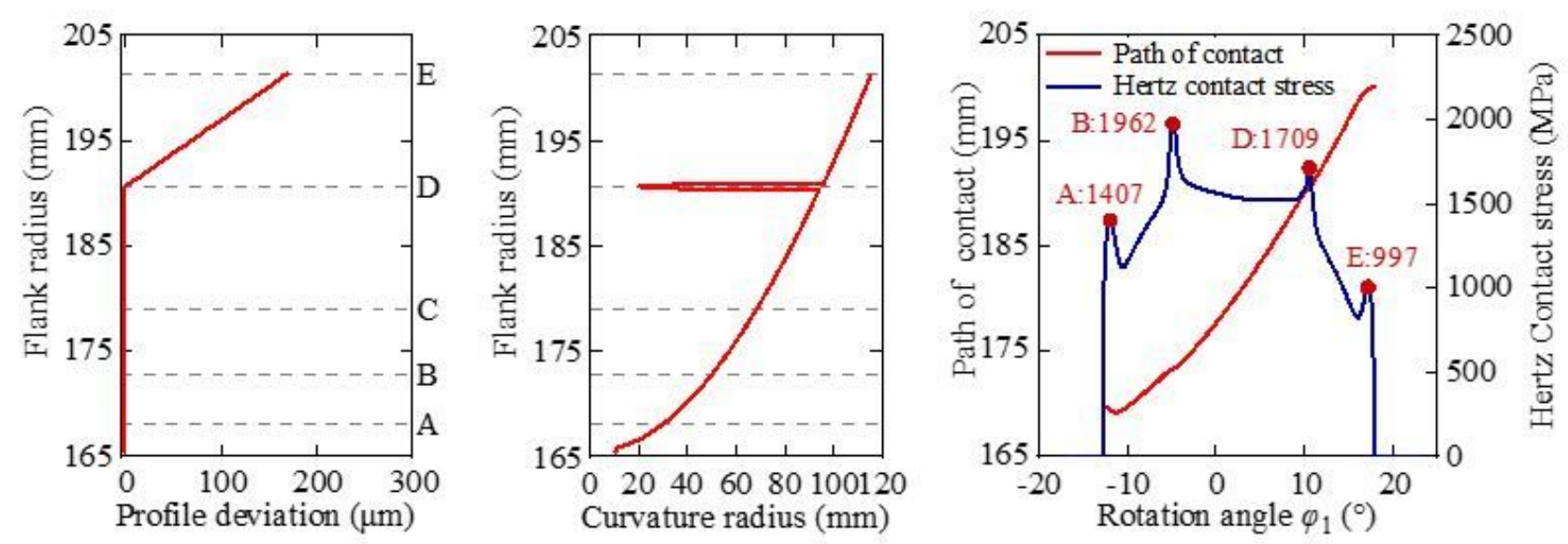

(b) Linear tip relief

\section{Figure 4}

Profile deviation, curvature radius, and Hertz contact stress (a) without tip relief and (b) with linear tip relief 


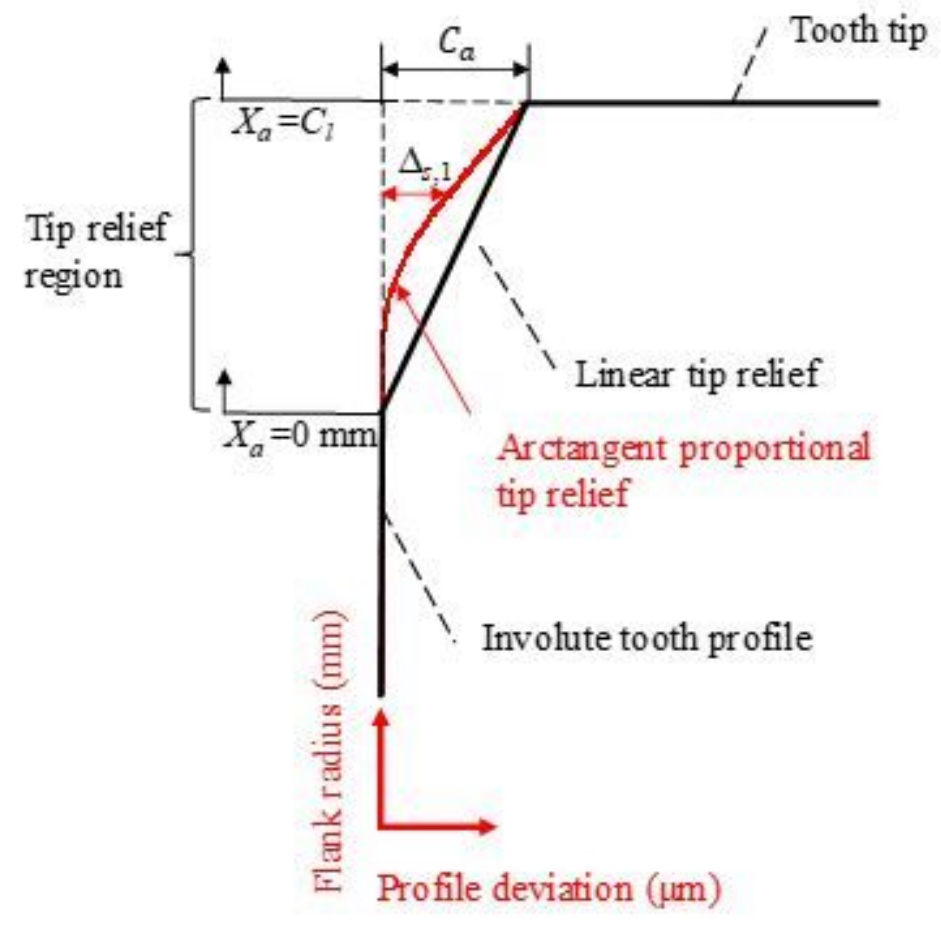

Figure 5

Flank radius versus profile deviation in arctangent-proportional tip relief 

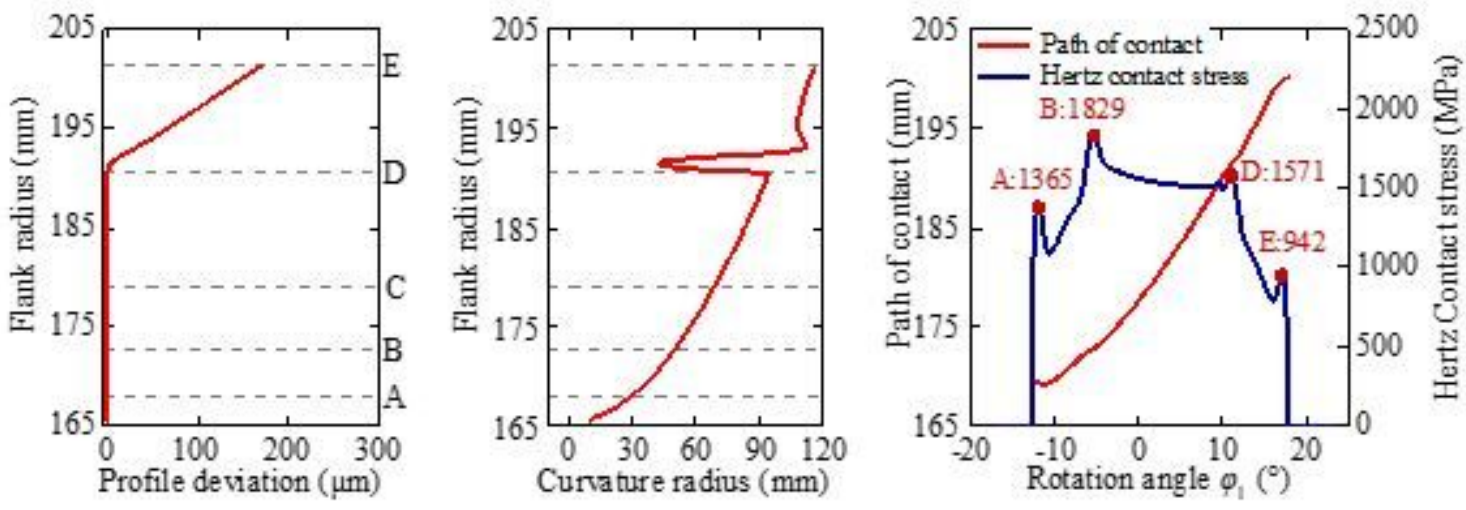

(a) Arctangent-proportional tip relief with $c=50$.
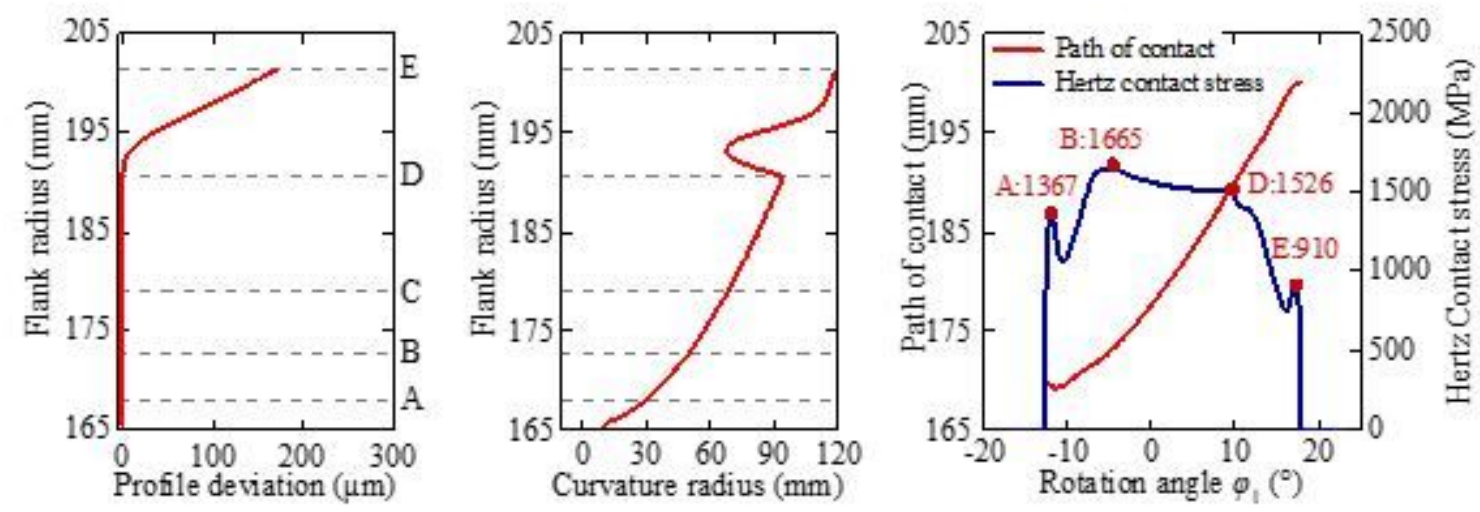

(b) Arctangent-proportional tip relief with $c=5$.
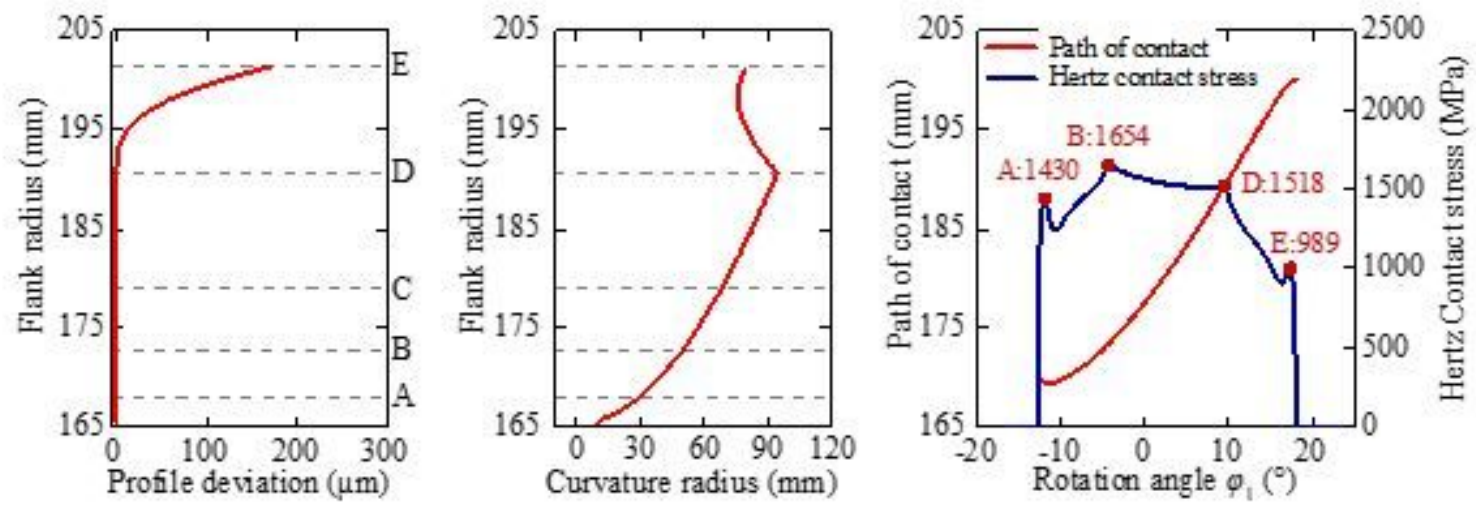

(c) Arctangent-proportional tip relief with $c=0.5$.

\section{Figure 6}

The effects on the tooth meshing of arctangent-proportional tip relief with different c 


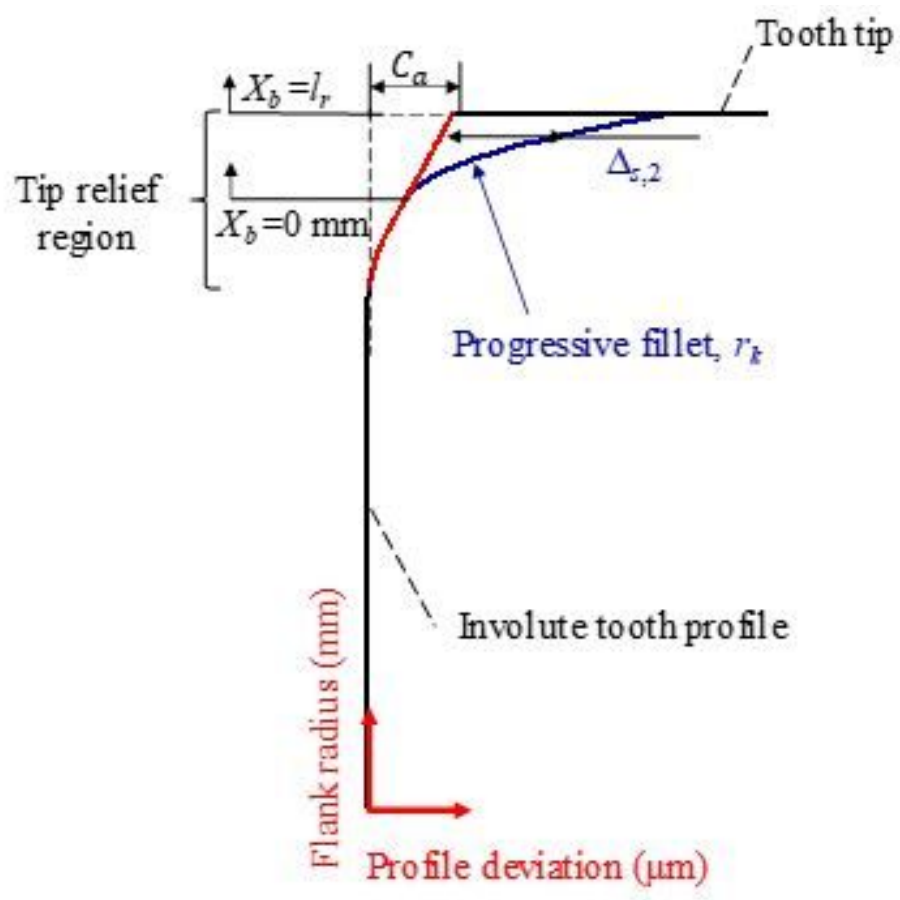

Figure 7

Flank radius versus profile deviation in the progressive fillet 

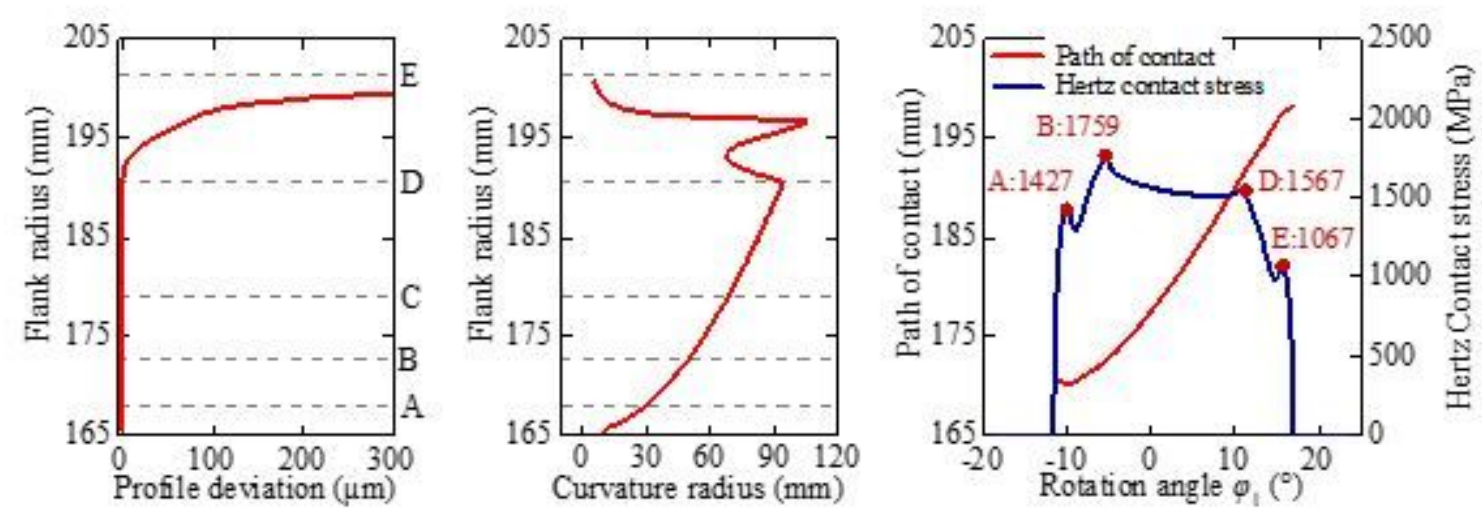

(a) $r_{k}=m / 3$
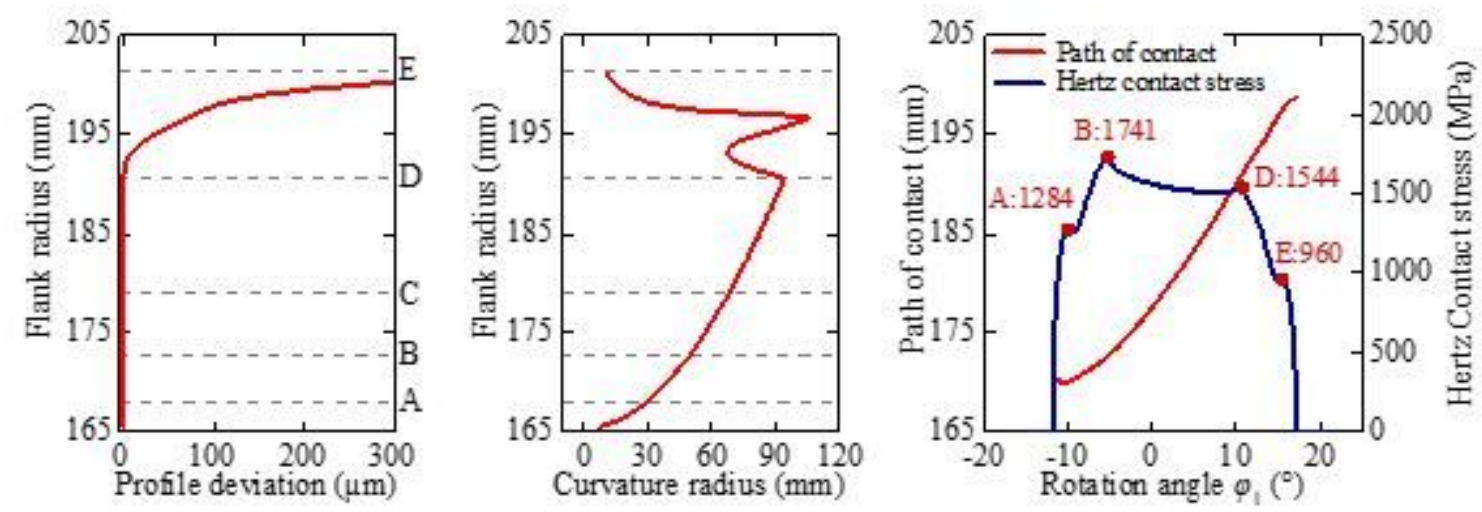

(b) $r=m / 2$
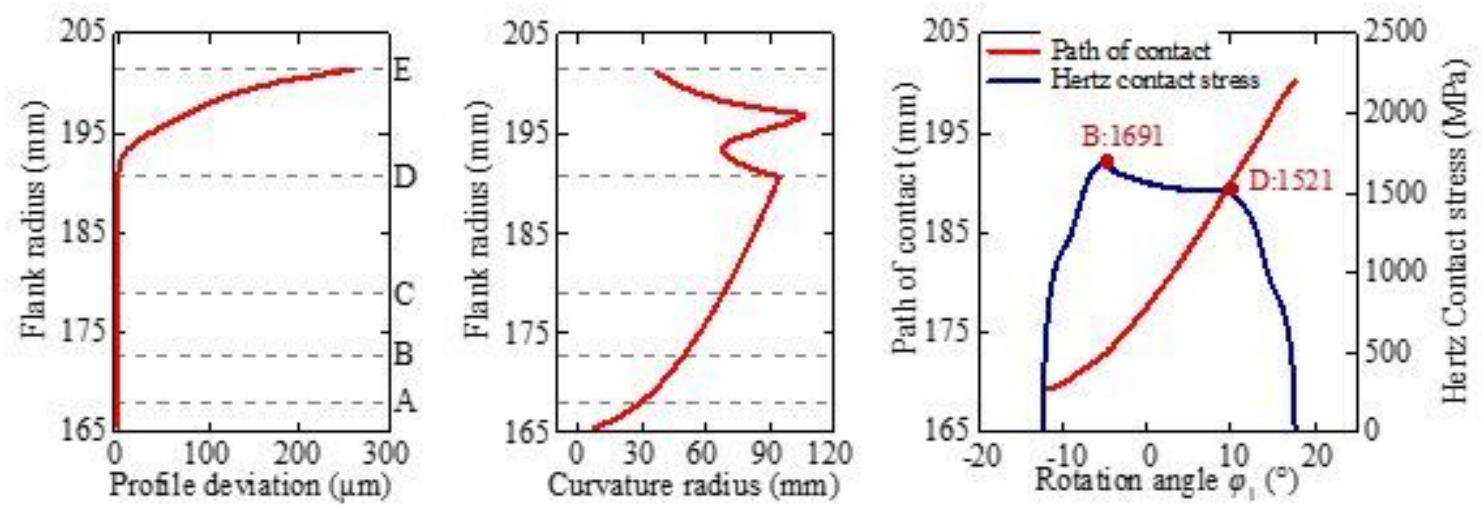

(c) $n=m n$

\section{Figure 8}

The effects on the tooth meshing by the progressive fillet with different geometrical parameters rk 

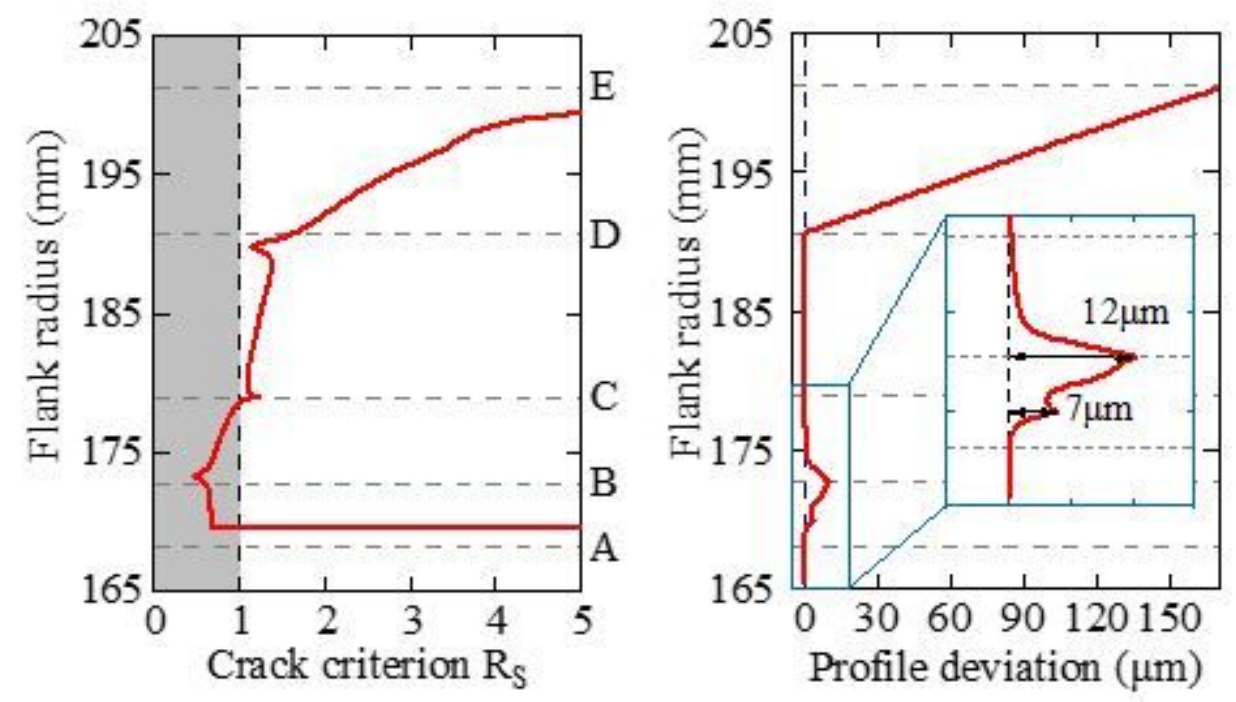

(a) Linear tip relief
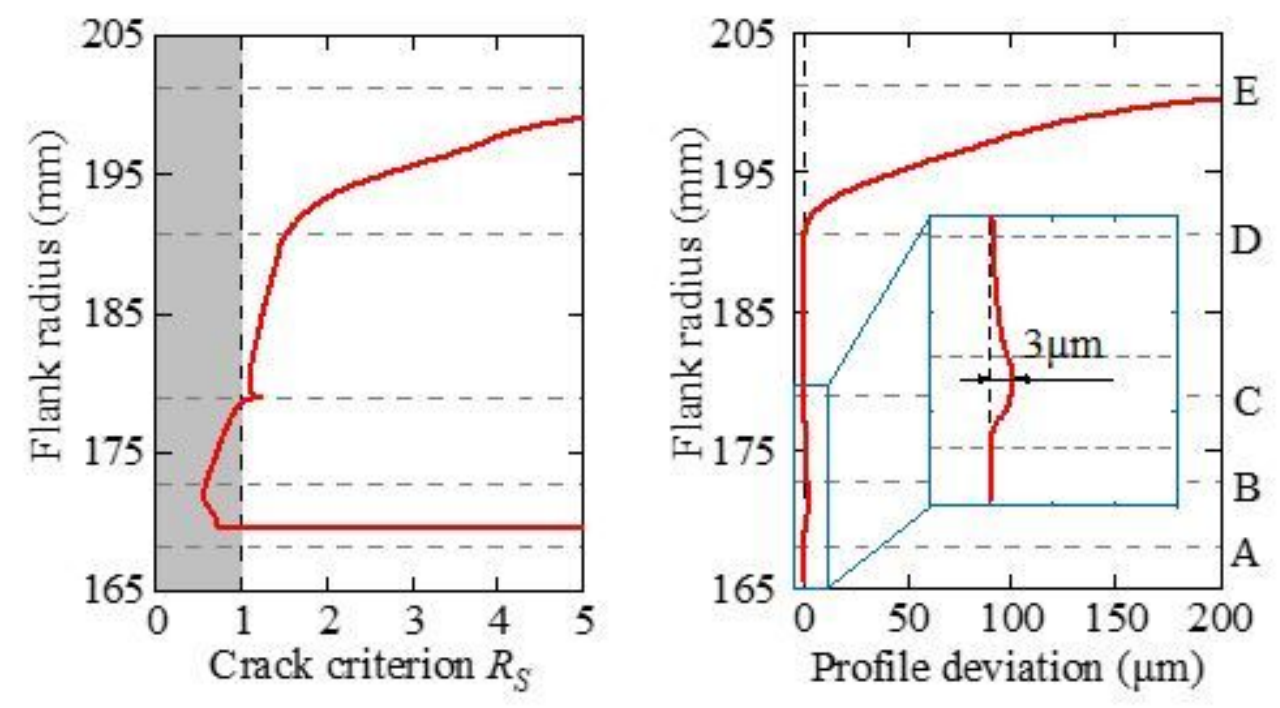

(b) Arctangent-proportional tip relief with a progressive fillet

\section{Figure 9}

Effects on micro-pitting of (a) linear tip relief and (b) arctangent-proportional tip relief with a progressive fillet 


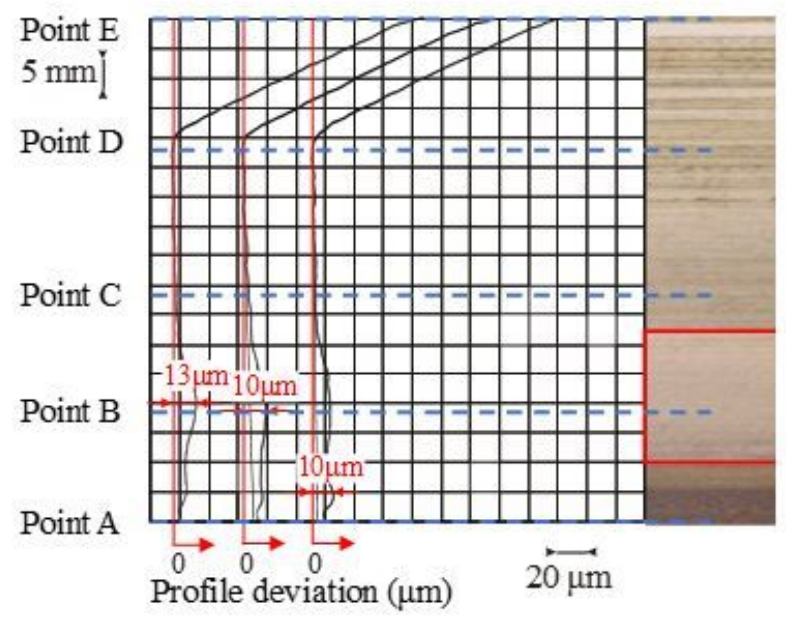

(a) The linear tip relief

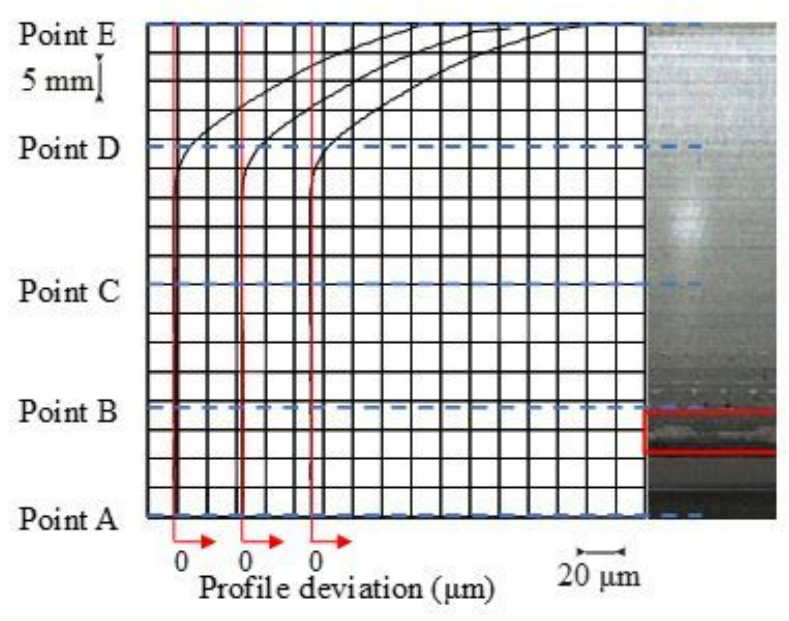

(b) The arctangent-proportional tip relief with a progressive fillet

Figure 10

Bench test results of profile deviation after tooth tip relief 